\title{
ELAV Proteins Bind and Stabilize C/EBP mRNA in the Induction of Long-Term Memory in Aplysia
}

\author{
${ }^{1}$ Anastasios A. Mirisis, ${ }^{1}$ Ashley M. Kopec, ${ }^{2}$ and Thomas J. Carew ${ }^{1}$ \\ ${ }^{1}$ Center for Neural Science, New York University, New York, New York 10003, and ${ }^{2}$ Department of Neuroscience and Experimental Therapeutics, \\ Albany Medical College, Albany, New York 12208
}

Long-term memory (LTM) formation is a critical survival process by which an animal retains information about prior experiences to guide future behavior. In the experimentally advantageous marine mollusk Aplysia, LTM for sensitization can be induced by the presentation of two aversive shocks to the animal's tail. Each of these training trials recruits distinct growth factor signaling systems that promote LTM formation. Specifically, whereas intact TrkB signaling during Trial 1 promotes an initial and transient increase of the immediate early gene apc/ebp mRNA, a prolonged increase in apclebp gene expression required for LTM formation requires the addition of TGF $\beta$ signaling during Trial 2 . Here we explored the molecular mechanisms by which Trial 2 achieves the essential prolonged gene expression of apclebp. We find that this prolonged gene expression is not dependent on de novo transcription, but that apc/ebp mRNA synthesized by Trial 1 is post-transcriptionally stabilized by interacting with the RNA-binding protein ApELAV. This interaction is promoted by p38 MAPK activation initiated by TGF $\beta$. We further demonstrate that blocking the interaction of ApELAV with its target mRNA during Trial 2 blocks both the prolonged increase in apc/ebp gene expression and the behavioral induction of LTM. Collectively, our findings elucidate both when and how ELAV proteins are recruited for the stabilization of mRNA in LTM formation. Stabilization of a transiently expressed immediate early gene mRNA by a repeated training trial may therefore serve as a "filter" for learning, permitting only specific events to cause lasting transcriptional changes and behavioral LTM.

Key words: Aplysia; c/ebp; ELAV; long-term memory; mRNA; post-transcriptional regulation

Significance Statement:

In the present paper, we significantly extend the general field of molecular processing in long-term memory (LTM) by describing a novel form of pretranslational processing required for LTM, which relies on the stabilization of a newly synthesized mRNA by a class of RNA binding proteins (ELAVs). There are now compelling data showing that important processing can occur after transcription of a gene, but before translation of the message into protein. Although the potential importance of ELAV proteins in LTM formation has previously been reported, the specific actions of ELAV proteins during LTM formation remained to be understood. Our new findings thus complement and extend this literature by demonstrating when and how this post-transcriptional gene regulation is mediated in the induction of LTM.

Received Aug. 31, 2020; revised 0ct. 22, 2020; accepted Nov. 23, 2020.

Author contributions: A.A.M., A.M.K., and T.J.C. designed research; A.A.M. and A.M.K. performed research; A.A.M. and A.M.K. analyzed data; A.A.M., A.M.K., and T.J.C. wrote the first draft of the paper; A.A.M., A.M.K., and T.J.C. edited the paper; A.A.M., A.M.K., and T.J.C. wrote the paper.

The authors declare no competing financial interests.

This work was supported by National Institute of Mental Health R01 MH 094792 to T.J.C. and a Hellenic Medical Society of New York Leonidas Lantzounis Research Grant to A.A.M. Figures were created with BioRender.com. We thank A. Alexandrescu, P.E. Miranda, and N.V. Kukushkin for comments on the manuscript; Bong-Kiun Kaang for sharing ApELAV plasmids; the Hochwagen Laboratory for use of the Deltavision Elite microscope for smFISH imaging; and the NYU Center for Genomics and Systems Biology Genomics Core for use of the Roche 480 LightCycler for qPCR experiments.

Correspondence should be addressed to Thomas J. Carew at tcarew@nyu.edu.

https://doi.org/10.1523/JNEUROSCI.2284-20.2020

Copyright @ 2021 Mirisis et al.

This is an open-access article distributed under the terms of the Creative Commons Attribution License Creative Commons Attribution 4.0 International, which permits unrestricted use, distribution and reproduction in any medium provided that the original work is properly attributed.

\section{Introduction}

Long-term memory (LTM) can be mechanistically distinguished from short-term and intermediate-term memory by its dependence on de novo transcription (Sutton et al., 2001; Alberini, 2009; Kandel, 2012). LTM for sensitization of the defensive tail and siphon withdrawal responses in Aplysia californica provides an experimentally advantageous system in which to study the molecular mechanisms underlying LTM formation. In this system, training trials (brief electrical shocks to the tail) lead to the release of the neuromodulator serotonin (5-HT) in the CNS of Aplysia (Marinesco and Carew, 2002), which in turn enhances synaptic transmission in the reflex circuit (Brunelli et al., 1976). Studies focusing on the sensory neurons (SNs) mediating these reflexes have elucidated critical molecular events underlying LTM for sensitization. For example, initiation of CREB-mediated transcription of several target genes, including the immediate early gene 
Aplysia clebp (apc/ebp), is required for LTM formation (Alberini et al., 1994; Alberini, 2009; Kandel, 2012; Mirisis et al., 2016).

As in many other species, the induction of LTM in Aplysia critically depends on the number and pattern of training trials. For example, two training trials separated by $45 \mathrm{~min}$ (but not by 15 or $60 \mathrm{~min}$ ) induce LTM formation (Philips et al., 2013), revealing a narrow time window during which a second trial interacts with a "molecular context" produced by the first trial to give rise to LTM formation (Philips et al., 2013).

In this paper, we explore the role of mRNA stabilization induced by growth factors (GFs) in LTM formation, with an emphasis on regulation that occurs between transcription and translation within the molecular context established by Trial 1 . Kopec et al. (2015) found that signaling through two distinct GF families, $\operatorname{TrkB}$ and $\operatorname{TGF} \beta$, is required during different training trials for the induction of the molecular events critical for LTM formation. Specifically, apc/ebp gene expression induced by Trial 1 peaked at $45 \mathrm{~min}$, was dependent on TrkB signaling, and returned to baseline by $1 \mathrm{~h}$ (Philips et al., 2013; Kopec et al., 2015). However, if Trial 2 was delivered during peak apc/ebp mRNA levels at $45 \mathrm{~min}$ after Trial 1, apc/ebp mRNA level remained elevated for $>1 \mathrm{~h}$, and this elevation critically required TGF $\beta$ signaling during Trial 2. Further, the induction of LTM required TrkB signaling during Trial 1 and TGF $\beta$ signaling during Trial 2 (Kopec et al., 2015).

Trial 2-dependent apc/ebp gene expression was directly dependent on the TrkB-mediated events set in motion by Trial 1 (Kopec et al., 2015). This dependence could be explained in one of two ways: (1) TGF $\beta$ signaling in Trial 2 also induces apclebp gene expression in Trial 2; or (2) TGF $\beta$ signaling in Trial 2 engages post-transcriptional mechanisms, which act to stabilize the apc/ ebp mRNA that was generated by TrkB signaling in Trial 1 .

In considering the second alternative, a candidate mechanism for the stabilization of the mRNA is the RNA-binding protein ELAV (embryonic lethal abnormal vision), which confers stability to mRNAs containing AU-rich elements (AREs) in their 3' UTR (Wang et al., 2000; Brennan and Steitz, 2001). Two ELAV family members, ApELAV1 and ApELAV2, have been identified and cloned in Aplysia, and ApELAV1 has been shown to bind to apclebp mRNA both in vitro and in vivo (Yim et al., 2006). Whereas ELAV proteins have been implicated in memory formation (Quattrone et al., 2001; Yim et al., 2006; Bolognani et al., 2007), these studies lacked temporal resolution and did not elucidate the mechanisms recruiting ELAV-mediated mRNA stabilization and its role in LTM formation.

In the present paper, we examine mRNA stabilization induced by ApELAV during LTM formation and show that it is specifically regulated by TGF $\beta$-induced p38 MAPK signaling initiated by Trial 2. Disrupting the ApELAV-apc/ebp interaction blocks the prolonged expression of apclebp mRNA, and this interaction is required for the behavioral induction of LTM. Collectively, these data demonstrate both when and how mRNA stabilization is achieved in LTM formation.

\section{Materials and Methods}

Experimental model and subject details

A. californica were acquired from South Coast Bio-Marine and University of Miami National Resource for Aplysia. All animals were allowed to acclimate for at least $4 \mathrm{~d}$ in circulating tanks with artificial sea water (ASW) (Instant Ocean) at $15^{\circ} \mathrm{C}$.

\section{Method details}

Ganglion preparation. Pleural-pedal ganglia were dissected from anesthetized A. californica (150-250 g). In a 1:1 solution of $\mathrm{MgCl}_{2}$ and ASW, the pleural SN cluster and SN-MN neuropil were exposed.
Ganglia were perfused with ASW for at least $1.5 \mathrm{~h}$ to clear $\mathrm{MgCl}_{2}$ before experimentation. Experimental and contralateral within-animal control ganglia both received GF/drug/vehicle treatment, while only the experimental ganglia received two-trial 5-HT training.

Training and drug incubation for gene expression analyses. After $\mathrm{MgCl}_{2}$ washout, two-trial analog training was delivered by two pulses of 5-HT ( $5 \mathrm{~min}$; $50 \mu \mathrm{M}$, Sigma Millipore, \#H9523-25MG) in ASW (ITI $=45 \mathrm{~min}$ ). As previously described (Kopec et al., 2015), ganglia in GF treatment experiments were blocked with BSA for at least $5 \mathrm{~min}$ pre-GF treatment, and GF/drug/vehicle was applied at the appropriate experimental time point. Drugs used were as follows: $\operatorname{rhTGF} \beta 1$ (R\&D Systems, \#240-B-002), rhTGF $\beta$ sRII (R\&D Systems, \#241-R2025), SB203580 (Tocris Bioscience, \#1202), Actinomycin D (ActinoD, Sigma Millipore, \#A1410-10MG), and CMLD-2 (Millipore, \#538339). Drug incubation was from $15 \mathrm{~min}$ before the training trial, during the training trial, and proceeded until SN cluster collection. Within-animal control ganglia concurrently received appropriate vehicle and mock two-trial training (pulses of ASW without 5-HT). Control and experimental SN clusters were collected at the experimental time point and prepared for either Western blotting or qPCR analysis.

RNA isolation, cDNA synthesis, qPCR analysis. RNA was isolated and purified using Ambion RNAqueous Micro kits (Invitrogen), and total RNA for cDNA synthesis was normalized between experimental and control ganglia ( $\sim 100 \mathrm{ng}$ RNA). cDNA was synthesized using Superscript IV cDNA synthesis reagents (Invitrogen). qPCR was performed using a Roche LightCycler 480 , with $1 \mu \mathrm{l}$ cDNA, $1 \mu \mathrm{l}$ each of $5 \mu \mathrm{M} \mathrm{F}^{\prime}$ and $\mathrm{R}^{\prime}$ primers, and $18 \mu \mathrm{l} 1 \times$ SYBR Green (Roche Diagnostics). Primer sequences are as follows: apc/ebp-F: caccacctcactcccatctc; apc/ ebp-R: ctgacgtctgcgagactttg; apgapdh-F: ctctgagggtgctttgaagg; apgapdhR: gttgtcgttgagggcaattc. The amplification program was $95^{\circ} \mathrm{C}$ for $3 \mathrm{~min}$, 30 cycles of $95^{\circ} \mathrm{C}$ for $10 \mathrm{~s}, 60^{\circ} \mathrm{C}$ for $20 \mathrm{~s}$, and $72^{\circ} \mathrm{C}$ for $30 \mathrm{~s}$, and last, a melting curve to confirm a single PCR product. Data were analyzed by normalizing the quantity of apc/ebp (measured by $\mathrm{C}_{\mathrm{t}}$ ) to apgapdh within the same sample $\left(\Delta \mathrm{C}_{\mathrm{t}}\right)$, then comparing normalized values between experimental and within-animal control groups $\left(\Delta \Delta \mathrm{C}_{\mathrm{t}}\right)$. Data are displayed as fold induction relative to the control group.

Western blotting. Samples were lysed and snap-frozen in RIPA buffer (Sigma Millipore) with $1 \times$ Halt protease and phosphatase inhibitor cocktail (Invitrogen), loaded onto $4 \%-12 \%$ Bis-Tris gels (Novex; Invitrogen) for electrophoresis, and then transferred to nitrocellulose membranes for incubation with primary antibodies and secondary antibodies: anti-HuR (1:1000; Santa Cruz Biotechnology, sc-5261), anti- $\beta$-actin (1:5000; Cell Signaling Technology, \#3700), anti-p-p38 MAPK (1:1000; Cell Signaling Technology, \#4511), anti- $\beta$-tubulin (1:5000; Cell Signaling Technology, \#2146), anti-mouse IgG IRDye 680LT (1:10,000; LICOR Biosciences, \#926$68020)$, and anti-rabbit IgG IRDye 800CW (1:10,000; LICOR Biosciences, \#926-32211). For ApELAV and p-p38 MAPK experiments, protein levels within each sample were assessed using the LICOR imaging system. Each protein of interest band was normalized to the tubulin or actin within the same sample, and normalized protein of interest in the experimental ganglia was compared with within-animal control ganglia. Data are displayed as fold expression of normalized protein of interest in experimental sample relative to control sample.

Single molecule FISH (smFISH). Aplysia SNs were individually isolated with a glass microelectrode from the ventral SN cluster of the pleural ganglion of $80 \mathrm{~g}$ animals according to Zhao et al. (2009) in $50 \mathrm{~mm}$ Mattek plates at $16^{\circ} \mathrm{C}$ with culture medium consisting of salt-adjusted L15 (Leibovitz) medium (Sigma; supplemented with $264 \mathrm{~mm} \mathrm{NaCl}$, $26 \mathrm{~mm} \mathrm{MgSO}_{4}, 27 \mathrm{~mm} \mathrm{MgCl}_{2}, 5 \mathrm{~mm} \mathrm{KCl}, 2 \mathrm{~mm} \mathrm{NaHCO}, 11 \mathrm{~mm} \mathrm{CaCl}_{2}$, $15 \mathrm{~mm}$ HEPES, $35 \mathrm{~mm}$ glucose, $2 \mathrm{~mm}$ L-glutamine, $100 \mathrm{U} / \mathrm{ml}$ penicillin, $0.1 \mathrm{mg} / \mathrm{ml}$ streptomycin) with $50 \%$ Aplysia hemolymph. SNs were distributed very sparsely throughout the coverglass. After $4 \mathrm{DIV}, 7$ plates of 10-20 SNs were chosen and separated into four different groups randomly. Two plates each were designated as " $2 \times 5-\mathrm{HT}+\mathrm{DMSO}$, , " $2 \times$ $5-\mathrm{HT}+\mathrm{SB}$," and " $2 \times$ ASW + DMSO." One plate received no treatments but was used as a "no probe" control to determine background fluorescence of SNs without DNA probes.

The smFISH protocol was adapted from Eliscovich et al. (2017). Following treatment according to the experimental paradigm (5-HT 
treatment was $50 \mu \mathrm{M}$ in ASW, ASW treatment was an equivalent volume of ASW), the cells were fixed for $30 \mathrm{~min}$ at room temperature in $4 \%$ formaldehyde in 30\% sucrose/DEPC-treated PBS with supplemented $1 \mathrm{~mm}$ magnesium chloride and $0.1 \mathrm{~mm}$ calcium chloride (DEPC-PBS$\mathrm{MC}$ ). Cells were washed quickly $2 \times$ with DEPC-PBS-MC and quenched with glycine in DEPC-PBS-MC. Quench buffer was removed, and cells were incubated in permeabilization-block buffer $(0.2 \%$ Triton X-100, $0.5 \%$ Ultrapure BSA in DEPC-PBS-MC) for $30 \mathrm{~min}$ at room temperature while shaking. Permeabilization-block buffer was removed, and cells were incubated with prehybridization buffer (10\% deionized formamide, $2 \times$ SSC, $0.5 \%$ Ultrapure BSA in nuclease-free water) for $30 \mathrm{~min}$ at room temperature without shaking. Prehybridization buffer was removed, and cells were incubated with hybridization buffer (10\% deionized formamide, $2 \times$ SSC, $1 \mathrm{mg} / \mathrm{ml}$ Escherichia coli tRNA, $20 \mathrm{mg} / \mathrm{ml} \mathrm{BSA}, 2 \times$ SSC, 2 mm vanadyl ribonucleoside complex, $10 \%$ dextran sulfate, $125 \mathrm{~nm}$ of DNA probes in nuclease-free water) for $4 \mathrm{~h}$ at $37^{\circ} \mathrm{C}$. Thirty-three DNA probes conjugated to Quasar 670 dye (LGC Biosearch Technology) were designed to be antisense to all regions on apc/ebp mRNA (Accession \#NP_001191392.1; NCBI) without significant complementarity to other mRNAs in the Aplysia Refseq database (NCBI). Cells were washed 4 times with $2 \times$ SSC and then once quickly with nuclease-free water. Coverslips were detached from the plates and mounted using Prolong Gold Antifade Reagent with DAPI (Invitrogen).

A Deltavision Elite imaging system (GE) equipped with Olympus $\times 60 / 1.42 \mathrm{NA}$ oil immersion lens and an InsightSSI Solid State Illumination module were used to image samples. Individual full SN somata were imaged in a $z$ stack with $500 \mathrm{~nm}$ spacing. Raw images were loaded into FISH-QUANT software (Mueller et al., 2013) and batch processed after detecting nucleus size (by DAPI) and tracing the outline of each SN. Initial analyses determined that, in the cells that received mock treatment $(2 \times$ ASW), the number of puncta counted in each cell was correlated strongly to the area of the cell nucleus, which corresponds to previous literature noting that the absolute amount of RNA can be dependent on cell size (Marguerat and Bähler, 2012). Therefore, the number of puncta counted in each cell was normalized to the area of the nucleus in each cell, as this value was calculated automatically by FISHQUANT.

Cross-linking immunoprecipitation (CLIP)- $q P C R$. The protocol was adapted from Yoon and Gorospe (2016). Experimental and within-animal contralateral control ganglia both received GF/drug/vehicle treatment, while only the experimental ganglia received two-trial 5-HT training. At $1 \mathrm{~h}$ following the onset of Trial 1, experimental and control ganglia were exposed to two consecutive pulses of $400 \mathrm{~mJ}$ UV light $(254 \mathrm{~nm})$ in a Stratagene Gene Linker to crosslink ribonucleoprotein complexes. Two pulses were used to ensure that UV light penetrated deep into the ventral SN cluster of the intact ganglion, as has been described for other tissues, such as triturated mouse brain (Darnell, 2012). SN clusters of 8 animals were collected and lysed in ice-cold NP40 lysis buffer (20 mM Tris- $\mathrm{HCl}, \mathrm{pH}$ 7.5, $100 \mathrm{~mm} \mathrm{KCl,} 5 \mathrm{~mm} \mathrm{MgCl}_{2}, 0.5 \%$ NP-40, 1 mм DTT) supplemented with $1 \times$ Halt protease and phosphatase inhibitor cocktail and $40 \mathrm{U} / \mathrm{ml}$ RNaseOUT (Invitrogen), and pooled for each experimental and contralateral control sample. Lysates were split into two fractions each and immunoprecipitated with either antibodies against HuR (Santa Cruz Biotechnology, sc-5261; see Fig. $3 F$ ) or normal mouse $\operatorname{IgG}_{1}$ (Santa Cruz Biotechnology, sc-3877) using Protein G Dynabeads (Invitrogen). Beads were washed with ice-cold NT-2 buffer (50 mм Tris-HCl, pH 7.5, $150 \mathrm{~mm} \mathrm{NaCl}, 1 \mathrm{~mm} \mathrm{MgCl}_{2}, 0.05 \% \mathrm{NP}-40$ ). Following consecutive digestions with DNase I and Proteinase K (New England Biolabs), beads were magnetically separated from the supernatant. RNA was isolated from the supernatant with Trizol extraction (Invitrogen), and cDNA was synthesized using Superscript IV cDNA synthesis reagents (Invitrogen). qPCR was performed as described above. Importantly, primers were designed to lie within the $3^{\prime}$ UTR of apclebp mRNA, the binding region of ELAV. The primer sequences were as follows: apc/ebpUTR-F: cccaagcatgttgtgatagttgt; apc/ebpUTR-R: tgggaggagatagaagcagtg. Data were analyzed by normalizing the difference in apclebp between ELAV- and IgG-immunoprecipitated samples to the difference in apgapdh between the same samples, then comparing these normalized values between experimental (two-trial training and drug-treated) and within-animal control (mock two-trial training and vehicle) groups.

ApELAV1 protein expression. The coding region for ApELAV1 was isolated by PCR from a previously published plasmid kindly provided by Bong-Kiun Kaang (Seoul National University) (Yim et al., 2006) and ligated into pGEX vector to make pGEX-ApELAV1-GST. Rosetta 2 DE3 cells (Millipore) were transformed with this plasmid, and cells were induced for $2 \mathrm{~h}$ at $37^{\circ} \mathrm{C}$ with $1 \mathrm{~mm}$ IPTG during log-phase growth. Cells were subsequently lysed and subjected to Western blotting.

Semi-intact behavioral preparation. Preparations were completed as previously described (Sutton et al., 2001; Kopec et al., 2015). Briefly, the ring ganglia (cerebral and paired pleural-pedal ganglia) from anesthetized Aplysia (250-400 g; South Coast Bio-Marine) were surgically isolated, leaving $\mathrm{p} 9$ and pleural-abdominal innervation to the tail and abdominal ganglia, respectively, intact. The tail and mantle were surgically removed, and the siphon artery was cannulated with Dow Corning SILASTIC tubing (0.025 in I.D.; Thermo Fisher Scientific) and perfused at $\sim 5 \mathrm{ml} / \mathrm{min}$, while the tail was perfused at $\sim 0.5 \mathrm{ml} / \mathrm{min}$ via three 22 gauge needles inserted into the tail. The tail and mantle were pinned to the chamber floor, while the ring ganglia with both pleural-pedal ganglia desheathed were pinned in an isolated CNS chamber. Both the chamber containing the peripheral tissues as well as the CNS chamber were continuously perfused with seawater (Instant Ocean, $15^{\circ} \mathrm{C}$ ). The p9 and pleural-abdominal nerves exited the CNS chamber through small slits that were sealed with Vaseline. Preparations were allowed at least $2 \mathrm{~h}$ to recover before baseline measurements.

Training and drug incubation for LTM analyses. An average of 3 or 4 baseline siphon-withdrawal measurements were recorded by stimulating the medial posterior tip of the tail with a water jet $(0.4 \mathrm{~s}, 45 \mathrm{psi}$; ITI 15 min; Teledyne Water Pik) and measuring the duration of time with which the siphon withdrew. No significant differences in the pretraining baseline duration of T-SWRs were observed in any experimental condition. The CNS was incubated with drug/vehicle 15 min before Trial 2, which was washed out $30 \mathrm{~min}$ after Trial 2. Two-trial LTM training $(100 \mathrm{~mA}, 1.5 \mathrm{~s}$, ITI $45 \mathrm{~min})$ was delivered medially to the anterior portion of the tail through a hand-held electrode. LTM for sensitization of the T-SWR was assessed by 3 or 4 tests (ITI $=15 \mathrm{~min}$ ) 15-22 h after training by an experimenter blind to the experimental condition (drug vs vehicle). The data are displayed as duration of siphon withdrawal as a percent of pretraining baseline.

\section{Quantification and statistical analysis}

Data were analyzed with parametric statistics using GraphPad Prism. Statistical details for all experiments can be found within the main text and/or in the figure legends. Within-group analyses were performed using paired $t$ test. LTM for sensitization of the T-SWR is compared relative to pretraining baseline T-SWR within the same preparation. Between-group analyses (drug vs vehicle) were performed using $t$ tests. When appropriate, ANOVAs were used to determine whether there was a difference among the groups and are indicated in the main text. Significant results were followed by planned parametric comparisons. Outliers $>2$ SDs from the mean were excluded resulting in the removal of 5 data points ( $<5 \%$ of all data points; reported in Results). Because of normal distribution of data, data in all figures are depicted as mean \pm SEM. Significant within-group comparisons are displayed as asterisks above the summary data, and significant between-group comparisons are displayed as asterisks above a bar drawn between the summary data.

\section{Results}

\section{The Trial 1-dependent increase in $a p c / e b p$ mRNA level is transcription-dependent}

We have shown that apc/ebp gene expression is increased $45 \mathrm{~min}$ following Trial 1 (Philips et al., 2013; Kopec et al., 2015). Thus, we first asked whether Trial 1-dependent increase in apclebp gene expression was because of (1) increased gene transcription or (2) alternative mechanisms, such as an increase in transcript stability of baseline levels of apc/ebp mRNA. 


\section{A}
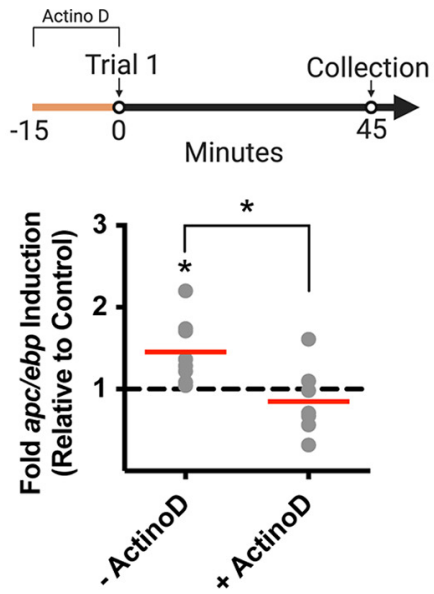

B
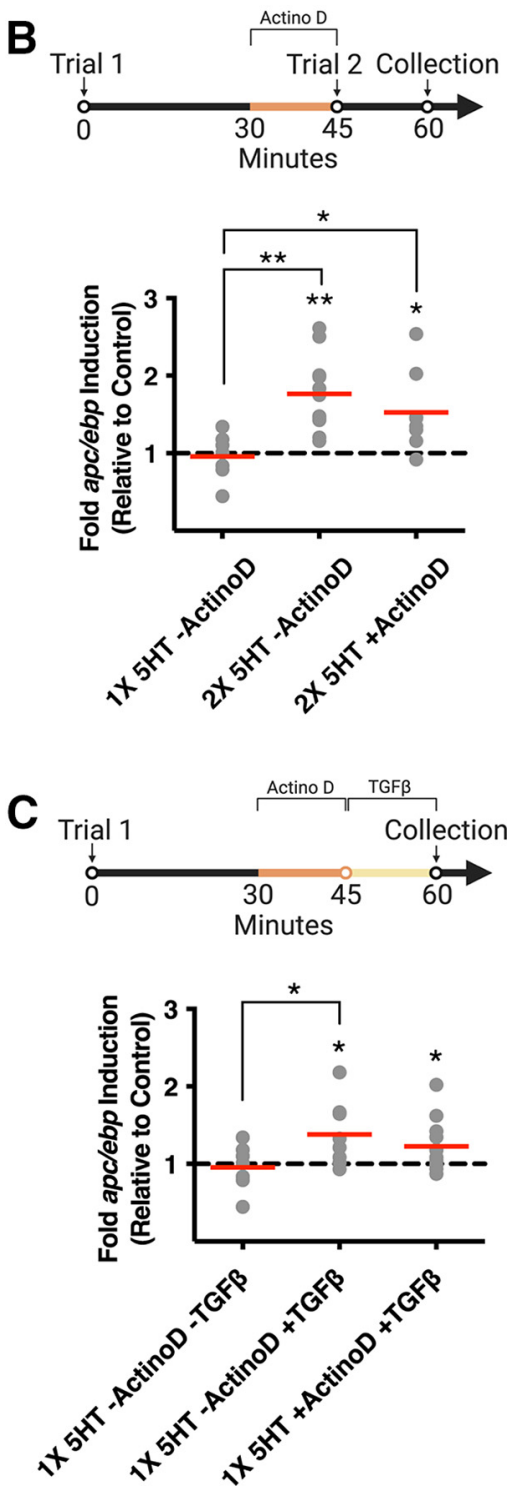

Figure 1. Trial 1 initiates a transcription-dependent increase in apc/ebp mRNA levels, whereas Trial 2 prolongs this gene expression through a transcription-independent mechanism. $\boldsymbol{A}$, Top, Experimental paradigm. Trial 1 is delivered at time $=0: 00$, and SN somata are collected at $45 \mathrm{~min}$ following the onset of Trial 1. Experimental ganglia are treated with ActinoD $15 \mathrm{~min}$ before Trial 1 (dark yellow line). Bottom, Blocking transcription before Trial 1 significantly disrupts apc/ebp gene expression at $45 \mathrm{~min}$. Histograms are labeled by their corresponding drug condition. Drug conditions are expressed as a ratio to vehicle conditions. In
In order to distinguish between these possibilities, we first conducted experiments to determine whether transcription was required for the Trial 1-dependent increase in $a p c / e b p$ gene expression. Dissected pleural-pedal ganglia were incubated with the irreversible transcription inhibitor Actinomycin D $(40 \mu \mathrm{g} / \mathrm{ml}$, Sigma Millipore) for $15 \mathrm{~min}$, and contralateral within-animal control ganglia were incubated with vehicle (an equivalent volume of $\mathrm{ddH}_{2} \mathrm{O}$ ). Following drug/vehicle washout, experimental ganglia were administered Trial 1 (50 $\mu \mathrm{m}$ 5-HT in ASW, Sigma Millipore) for $5 \mathrm{~min}(1 \times 5$-HT) to simulate a tail shock training trial (Philips et al., 2013). Within-animal contralateral control ganglia were administered mock Trial 1 (pulse of ASW without 5-HT). Five minutes following pulse onset, ganglia were washed with fresh ASW, and pleural SN clusters were collected at $45 \mathrm{~min}$ and analyzed for $a p c / e b p$ gene expression via qPCR. No significant difference in $a p c / e b p$ gene expression was observed between (1) experimental ganglia, which received Trial 1 in the presence of ActinoD, and (2) within-animal control ganglia, which received mock training in the presence of vehicle (Fig. 1A; within-group paired $t$ test: +ActinoD: $n=7,0.8505 \pm 0.1601$, $p=0.3865$ ). In this and following experiments, the ratio of $a p c /$ ebp gene expression in experimental ganglia to contralateral control ganglia was calculated for each pair of ganglia (data in histograms are represented as a ratio of drug conditions to vehicle conditions). Consistent with previous results (Kopec et al., 2015), a within-group comparison revealed a significant increase in apc/ $e b p$ gene expression in experimental SN clusters collected $45 \mathrm{~min}$ after Trial 1 without drug treatment, compared with within-animal contralateral control ganglia, which received mock Trial 1 without drug treatment (Fig. 1A; within-group paired $t$ test: ActinoD: $n=8,1.456 \pm 0.140, p=0.0139$ ). A between-group comparison revealed a significant difference between $a p c / e b p$ gene expression of SN clusters, which had received Trial 1 with ActinoD compared with SN clusters, which had received Trial 1 without ActinoD (Fig. 1A; between-group unpaired $t$ test: ActinoD vs + ActinoD: $t=2.862, \mathrm{df}=13, p=0.0134$ ), demonstrating that Trial 1-dependent apclebp gene expression at $45 \mathrm{~min}$ after Trial 1 is dependent on de novo gene transcription.

\section{The Trial 2-dependent increase in apc/ebp mRNA level is transcription-independent}

When Trial 2 is delivered $45 \mathrm{~min}$ after Trial 1, apc/ebp gene expression at $1 \mathrm{~h}$ after Trial 1 is dependent on (1) TrkB signaling during Trial 1 and (2) TGF $\beta$ signaling during Trial 2 (Kopec et al., 2015). This suggests that either (1) Trial $2 \operatorname{TGF} \beta$-dependent mechanisms cause a new wave of apclebp transcription or (2) Trial 2 induces a form of transcription-independent stabilization

$\leftarrow$

this and all subsequent figures, unless specified otherwise, data are displayed as aligned dot plots. Red lines within each histogram indicate means. Within-group statistical significance is displayed with an asterisk within histograms, and between-group statistical significance is indicated above the histograms being compared. $n=7$ or $8 . * p<0.05$. For full statistical details, see Results. $\boldsymbol{B}$, Top, Experimental paradigm. SN somata are collected at $1 \mathrm{~h}$ following the onset of Trial 1. Experimental ganglia are treated with ActinoD at 30-45 min (dark yellow line). Bottom, A second training trial (Trial 2) at 45 min following the onset of Trial 1 results in a transcription-independent significant increase in apc/ebp gene expression at $1 \mathrm{~h} . n=7$ 11. $* p<0.05 . * * p<0.01$. C, Top, Experimental paradigm. SN somata are collected at $1 \mathrm{~h}$ following the onset of Trial 1. Experimental ganglia are treated with ActinoD at 30-45 min (dark yellow line). TGF $\beta 1$ is applied at 45 min until collection (light yellow line). Bottom, Treatment with TGF $\beta 1$ alone at 45 min results in a transcription-independent increase in apc/ebp mRNA level. $1 \times 5-H \mathrm{HT}-$ ActinoD $-\mathrm{TGF} \beta$ group control data are from $\boldsymbol{B} . n=7-12$. $* p<0.05$. 
of apc/ebp mRNA synthesized from Trial 1 (via TrkB-dependent mechanisms). Experimental ganglia were treated with ActinoD for $15 \mathrm{~min}$ before Trial 2 (30 min following Trial 1). Following drug washout, experimental ganglia were exposed to 5 -HT for $5 \mathrm{~min}$ (Trial 2), thus receiving two-trial training $(2 \times 5-\mathrm{HT}) .5$-HT was washed out with fresh ASW, and pleural SN clusters were collected at $1 \mathrm{~h}$ after Trial 1 . In this and subsequent experiments where experimental ganglia are trained with two-trial training, within-animal contralateral control ganglia received mock two-trial training ( 5 min pulses of ASW without 5 -HT) and vehicle. A within-group analysis revealed a significant increase in apc/ebp mRNA levels in ganglia, which had received two-trial training, even in the presence of ActinoD before Trial 2 (Fig. 1B; within-group paired $t$ test: $2 \times 5$-HT - ActinoD: $1.765 \pm 0.1463, n=11, p=$ 0.0004; $2 \times 5$-HT + ActinoD: $1.527 \pm 0.1830, n=8, p=0.0237)$. Consistent with previous findings (Kopec et al., 2015), Trial 1 alone was not sufficient for apclebp gene expression $1 \mathrm{~h}$ later (Fig. $1 B$; within-group paired $t$ test: $1 \times 5-\mathrm{HT}-$ ActinoD: $0.9600 \pm$ $0.1118, n=7, p=0.7325)$. ANOVA revealed a significant difference among the three groups $(F=6.786 ; p=0.0048)$. Subsequent planned $t$ tests revealed a significant increase in apclebp mRNA levels in both the $2 \times 5-\mathrm{HT}-$ ActinoD and $2 \times 5-\mathrm{HT}+$ ActinoD groups, compared with ganglia that had received only Trial $1(1 \times$ $5-\mathrm{HT})$, and no significant difference was noted between the $2 \times$ 5 -HT - ActinoD and $2 \times 5$-HT + ActinoD groups (Fig. $1 B$; between-group unpaired $t$ test: $1 \times 5-\mathrm{HT}-$ ActinoD vs $2 \times 5$-HT -ActinoD: $t=3.926, \mathrm{df}=16, p=0.0012 ; 1 \times 5$-HT - ActinoD vs $2 \times 5$-HT +ActinoD: $t=2.550, \mathrm{df}=13, p=0.0242 ; 2 \times$ 5 -HT - ActinoD vs $2 \times 5-\mathrm{HT}+$ ActinoD: $t=1.028, \mathrm{df}=17, p=$ $0.3181)$. These data demonstrate that the Trial 2-dependent increase in $a p c / e b p$ mRNA level at $1 \mathrm{~h}$ after Trial 1 is not dependent on de novo gene transcription and supports the hypothesis that the increased $a p c / e b p$ mRNA level may result from TGF $\beta$-dependent mRNA stabilization.

\section{TGF $\beta 1$ treatment at $\mathbf{4 5} \mathbf{m i n}$ is sufficient for Trial 2- dependent increase in apc/ebp mRNA level}

By sequestering endogenously released TGF $\beta$-like ligands during Trial 2 , we have previously shown that intact TGF $\beta$ signaling is required during Trial 2 for apclebp gene expression at $1 \mathrm{~h}$ (Kopec et al., 2015). We here sought to determine whether treatment with recombinant human TGF $\beta 1$ alone could duplicate these effects.

To investigate this question, ganglia were treated with TGF $\beta 1$ (100 ng/ml, R\&D Systems) starting at $45 \mathrm{~min}$ after Trial 1 until SN cluster collection and lysis at $1 \mathrm{~h}$ after Trial 1 (Trial 2 was not administered). Treatment with TGF $\beta 1$ has previously been demonstrated to (1) recruit persistent ERK signaling, a necessary step in LTM formation; and (2) induce long-term facilitation in isolated Aplysia ganglia (Zhang et al., 1997; Shobe et al., 2016). Contralateral control ganglia received mock Trial 1 and were treated with an equivalent volume of vehicle $(0.1 \%$ BSA in ASW). Treatment with TGF $\beta 1$ resulted in a significant increase in apc/ebp mRNA levels compared with within-animal controls that had received only vehicle (Fig. $1 C$; within-group paired $t$ test: $1 \times 5$-HT -ActinoD + TGF $\beta$ : $1.384 \pm 0.1493, n=8, p=0.0369$ ). Between-group comparisons further revealed a significant difference between the Trial 1 only and Trial $1+$ TGF $\beta$-treated groups (Fig. $1 C$; betweengroup unpaired $t$ test: $1 \times 5$-HT - ActinoD - TGF $\beta$ vs $1 \times 5-\mathrm{HT}$ -ActinoD + TGF $\beta: t=2.219, \mathrm{df}=13, p=0.0449$ ).

Given that TGF $\beta 1$ treatment at 45 min after Trial 1 is sufficient to increase apc/ebp mRNA level at $1 \mathrm{~h}$ (Fig. 1C), we further asked whether the TGF $\beta$ signaling-dependent effect of increased $a p c / e b p$ mRNA levels at $1 \mathrm{~h}$ after Trial 1 required transcription. Ganglia were treated at $30 \mathrm{~min}$ after Trial 1 with ActinoD. At 45 min after Trial 1, ActinoD was washed out and ganglia were immediately treated with TGF $\beta 1$ until SN cluster collection and lysis at $1 \mathrm{~h}$ after Trial 1 . Contralateral within-animal control ganglia received mock Trial 1 and vehicle $(0.1 \%$ BSA in ASW and $\left.\mathrm{ddH}_{2} \mathrm{O}\right)$. TGF $\beta 1$ treatment concomitant with a transcriptional block still resulted in significantly increased apc/ebp mRNA level compared with within-animal contralateral control ganglia (Fig. $1 C$; within-group paired $t$ test: $1 \times 5$-HT + ActinoD + TGF $\beta$ : $1.230 \pm 0.0954, n=12, p=0.0345)$. Moreover, there was no significant difference between groups that received TGF $\beta$ treatment alone and TGF $\beta$ treatment with ActinoD (Fig. 1C; between-group unpaired $t$ test: $1 \times 5$-HT - ActinoD + TGF $\beta$ vs $1 \times 5$-HT +ActinoD + TGF $\beta: t=0.9160, \mathrm{df}=18, p=0.3718$ ). Collectively, these data support the hypothesis that TGF $\beta$ signaling during Trial 2 is responsible for the post-transcriptional stabilization effect on apc/ebp mRNA.

\section{p38 MAPK is activated by two-trial training and is blocked by blocking TGF $\beta$ signaling}

Our findings raise the important question of how Trial 2 prolongs apclebp gene expression through a transcription-independent mechanism downstream of TGF $\beta$ signaling. To examine this question, we investigated a particular kinase, p38 MAPK, which is both activated downstream of TGF $\beta$ signaling (Yamashita et al., 2008) and plays a cellular role in brokering to regulating mRNA stability (Varela-Rey et al., 2002; Dean et al., 2003; Soni et al., 2019). Thus, we assayed p38 MAPK activation in the pleural SNs following two-trial training. Our experiments revealed a significant increase in p38 MAPK activation in SNs following two-trial training in experimental ganglia compared with within-animal contralateral control ganglia (Fig. $2 A$; within-group paired $t$ test: $2 \times 5$-HT: $1.845 \pm 0.232, n=6, p=0.0148)$. This increase was blocked either (1) by eliminating Trial 2 or (2) by delivering Trial 2 in the presence of TGF $\beta$ sRII ( $5 \mu \mathrm{g} / \mathrm{ml}$, R\&D Systems), the soluble extracellular portion of the human Type-II TGF $\beta$ receptor, which acts as an inhibitor of TGF $\beta$ signaling by sequestering extracellular ligands, preventing their association with the endogenous Aplysia TGF $\beta$ receptor (Kopec et al., 2015) (Fig. $2 A$; within-group paired $t$ test: $1 \times 5$-HT: $1.089 \pm 0.184, n=7$, $p=0.9975 ; 2 \times 5$-HT + TGF $\beta$ sRII: $1.148 \pm 0.086, n=7, p=0.25$; between-group unpaired $t$ test: $1 \times 5$-HT vs $2 \times 5$-HT: $t=2.582$, $\mathrm{df}=11, p=0.0255 ; 2 \times 5$-HT vs $2 \times 5$-HT + TGF $\beta$ sRII: $t=2.996$, $\mathrm{df}=11, p=0.0122$ ). These data demonstrate that $\mathrm{p} 38 \mathrm{MAPK}$ activation at $1 \mathrm{~h}$ is dependent on TGF $\beta$ signaling and may serve an intermediate role between TGF $\beta$ signaling and $a p c / e b p$ mRNA stabilization.

\section{p38 MAPK activation is required for prolonged increase in apc/ebp mRNA levels}

To further examine the role of p38 MAPK in the stabilization of $a p c / e b p$ mRNA, we directly measured $a p c / e b p$ mRNA levels, by performing smFISH on isolated Aplysia SNs. This technique allows for fluorescent visualization of individual apc/ebp RNA molecules as puncta resulting from the combined fluorescence of 33 antisense DNA probes (LGC Biosearch Technology) (Fig. 2B1). ANOVA revealed a significant difference in puncta abundance between: (1) SNs that received two-trial training in the presence of vehicle ( $2 \times 5$-HT + DMSO); (2) SNs that received two-trial training in the presence of SB203580, a p38 MAPK inhibitor previously 
used and characterized in Aplysia (Zhang et al., 2017) $(10 \mu \mathrm{M}$, Tocris Bioscience) $(2 \times 5-\mathrm{HT}+\mathrm{SB})$; and (3) SNs that received vehicle and mock twotrial training $(2 \times \mathrm{ASW}+\mathrm{DMSO})$ (Fig. 2B2; $F=7.804, p=0.0010)$. Planned $t$ tests revealed a significant increase in puncta in SNs that received two-trial training in the presence of DMSO compared with each of the other groups (Fig. 2B2; within-group paired $t$ test: $2 \times 5-\mathrm{HT}+\mathrm{DMSO}$ : $186.9 \pm 23.85 \%, n=23, p=0.0014,1$ outlier; $2 \times$ $5-\mathrm{HT}+\mathrm{SB}: 94.82 \pm 15.74 \%, n=15, p=0.7471,2$ outliers; $2 \times$ ASW + DMSO: $100 \pm 12.74 \%, n=23$, 1 outlier, $p=0.9999$; between-group unpaired $t$ test: $2 \times 5-\mathrm{HT}+\mathrm{DMSO}$ vs $2 \times 5-\mathrm{HT}+\mathrm{SB}: t=2.855$, $\mathrm{df}=36, p=0.0071 ; 2 \times 5-\mathrm{HT}+\mathrm{DMSO}$ vs $2 \times \mathrm{ASW}$ + DMSO: $t=3.213, \mathrm{df}=44, p=0.0025)$.

We used qPCR to examine whether p38 MAPK activation is important for the increase in apc/ebp mRNA level $1 \mathrm{~h}$ after Trial 1 in ganglia. Experimental ganglia received two-trial training with SB203580 treatment during Trial 2 until SN cluster collection and lysis at $1 \mathrm{~h}$. Within-animal contralateral control ganglia were treated with vehicle ( $0.1 \%$ DMSO) and received mock two-trial training. Treatment with SB203580 during Trial 2 blocked the Trial 2-dependent increase in apc/ebp mRNA levels compared with two-trial training alone (Fig. 2C; within-group paired $t$ test: $2 \times$ $5-\mathrm{HT}+\mathrm{SB}: 0.7341 \pm 0.161, n=8, p=0.1423$; between-group unpaired $t$ test: $2 \times 5$-HT vs $2 \times$ $5-\mathrm{HT}+\mathrm{SB}: t=4.692, \mathrm{df}=17, p=0.0002)$.

\section{ApELAV-mRNA interaction is required for} prolonged increase in $a p c / e b p$ mRNA levels Our findings thus far demonstrate that p38 MAPK activation downstream of TGF $\beta$ signaling resulting from Trial 2 is required for the stabilization of apc/ebp mRNA. The RNA-binding protein ApELAV has been previously shown to bind $a p c /$ ebp mRNA in Aplysia by associating with AREs in the $3^{\prime}$ UTR (Yim et al., 2006). Since ELAV is known to be an RNA-binding protein yielding a stabilizing effect on its target mRNAs (Brennan and Steitz, 2001; Yim et al., 2006), we explored the possibility that $a p c / e b p$ gene expression is modulated by ApELAV. In support of this possibility, p38 MAPK has previously been identified as a critical mediator of ELAV activation by phosphorylation (Pascale et al., 2005; Lafarga et al., 2009; Bai et al., 2012; Eberhardt et al., 2012; Slone et al., 2016).

In order to directly manipulate the ability of ApELAV to interact with its target transcripts, we used CMLD-2 (100 $\mu \mathrm{M}$, Millipore), a potent inhibitor of HuR-ARE interaction (Wu et al., 2015; Slone et al., 2016; Muralidharan et al., 2017). HuR is a mammalian homolog of ELAV, and also contains three highly conserved RNA recognition motifs, which facilitate its binding to AREs of mRNAs. Since CMLD-2 directly binds to the highly evolutionary conserved RNA-binding pocket of HuR, we hypothesized that it would likewise bind and inhibit ApELAV binding.
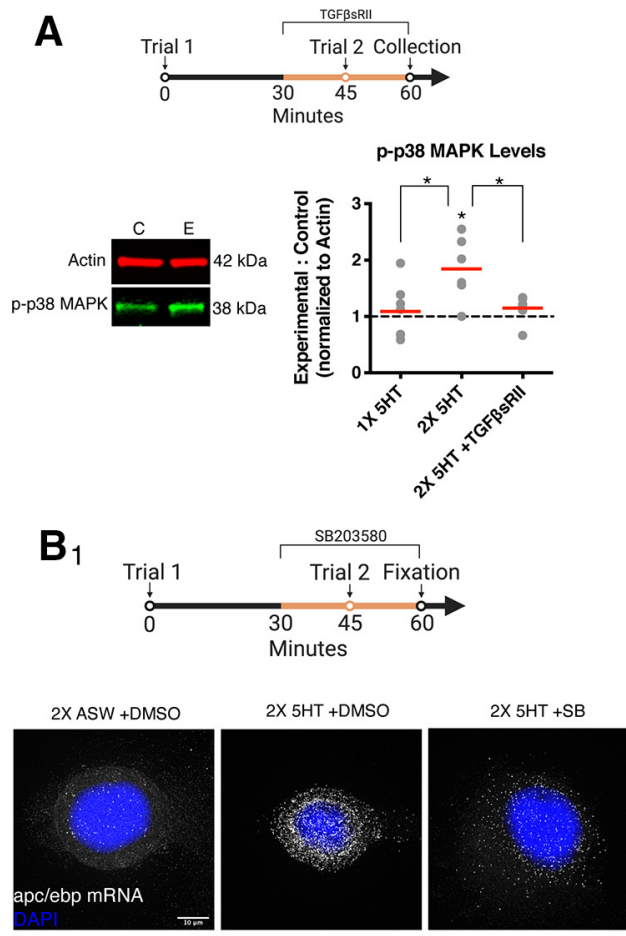

$\mathbf{B}_{2}$

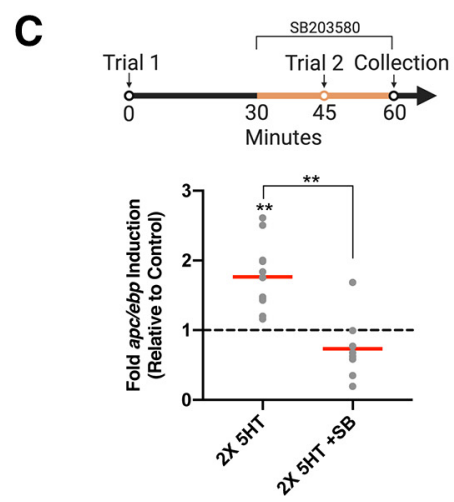

Figure 2. Prolonged expression of apc/ebp mRNA requires p38 MAPK activity initiated by TGF $\beta$ signaling. $\boldsymbol{A}$, Top, Experimental paradigm. SN somata are collected at $1 \mathrm{~h}$ following the onset of Trial 1. Experimental ganglia receive two-trial training and are treated with TGF $\beta$ sRII (dark yellow line) from 30 min until collection at $1 \mathrm{~h}$. Bottom, Left, Representative Western blot for p-p38 MAPK using actin as a loading control. Control (C) and experimental (E) indicate bands from a single SN cluster pair $(n=1)$ in the $2 \times 5-\mathrm{HT}$ treatment group. Right, Following two-trial training, there is a significant increase in p38 MAPK activation, which is blocked by treatment with TGF $\beta$ sRII. $n=6$ or $7 . * p<0.05$. $\boldsymbol{B}_{1}$, Top, Experimental paradigm. SNs are fixed at $1 \mathrm{~h}$ following the onset of Trial 1. Experimental plates of SNs receive two-trial training and are treated with SB203580 (dark yellow line) from 30 min until fixation at $1 \mathrm{~h}$. Bottom, Representative maximum $\mathrm{z}$-projection widefield microcopy images of isolated SNs subjected to smFISH. White puncta are apc/ebp mRNA. Blue represents nuclei (stained with DAPI). Scale bar, $10 \mu \mathrm{m} . \boldsymbol{B}_{2}$, Following two-trial training, apc/ebp mRNA levels are increased in SNs, and this increase is blocked by blocking p38 MAPK activation. Data are represented as a percentage of normalized puncta abundance in SNs, which received mock two-trial training in the presence of vehicle. $n=19-23 . * * p<0.01$. C, Top, Experimental paradigm. SN somata are collected at $1 \mathrm{~h}$ following the onset of Trial 1. Experimental ganglia receive two-trial training and are treated with SB203580 (dark yellow line) from 30 min until collection at $1 \mathrm{~h}$. SN clusters are subjected to qPCR. Bottom, Following two-trial training, there is a significant increase in apclebp mRNA levels, which is blocked by blocking p38 MAPK activation during Trial 2.The $2 \times 5$-HT control data are from Figure $1 B$. $n=8-11 . * * p<0.01$.

In order to test whether CMLD-2 blocks the interaction between ApELAV and $a p c / e b p$ mRNA, we performed experiments assaying the stability of apc/ebp mRNA following transcriptional block (to inhibit basal transcription) both with and without CMLD-2 treatment. We found that treatment with both ActinoD alone and ActinoD + CMLD-2 for 40 min resulted in a significant 
A

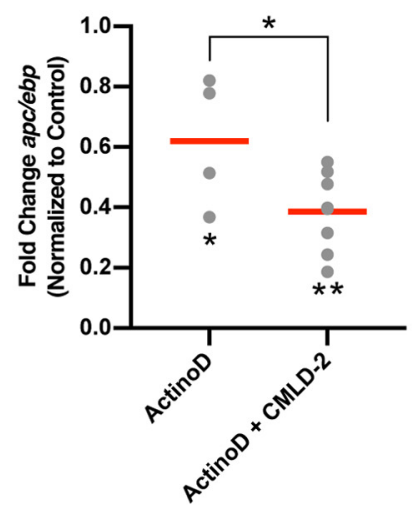

D
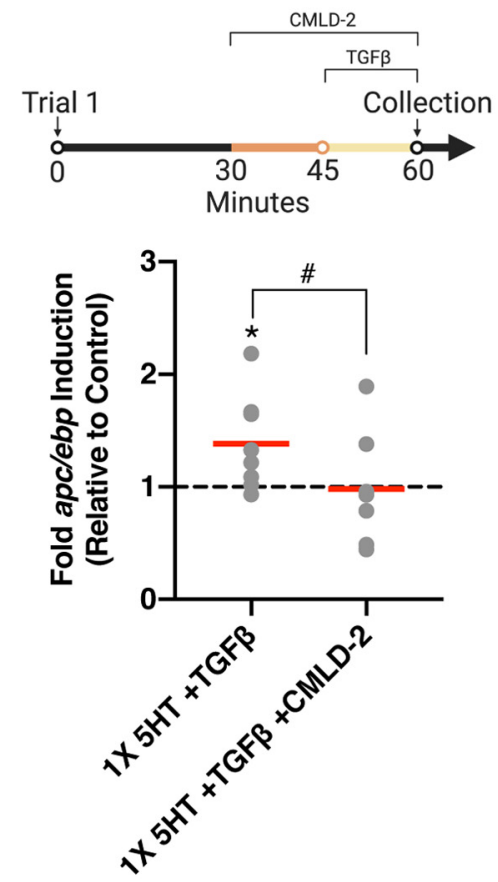

B
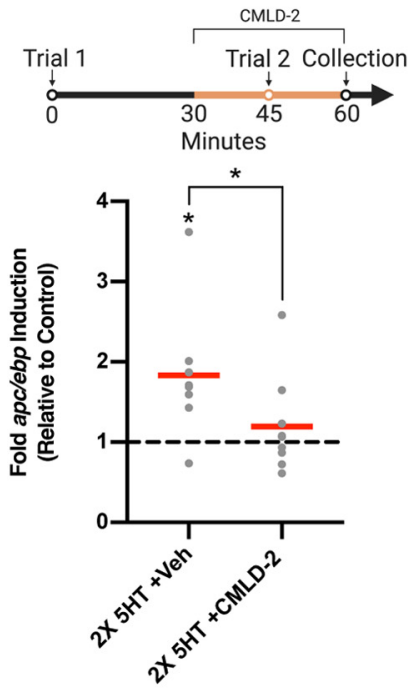

$\mathbf{F}$

- IPTG +IPTG

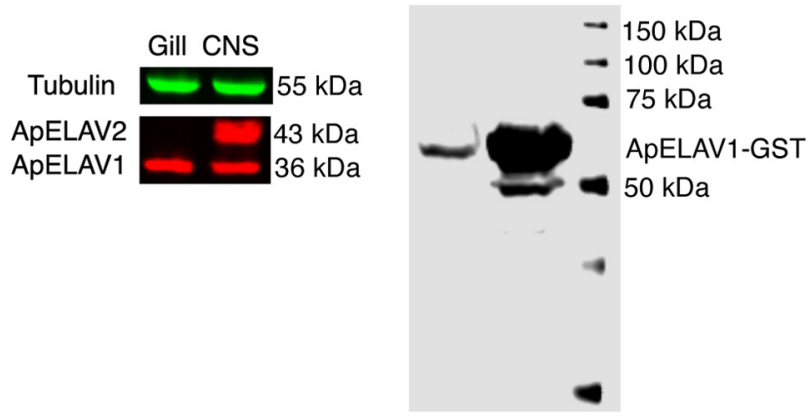

E

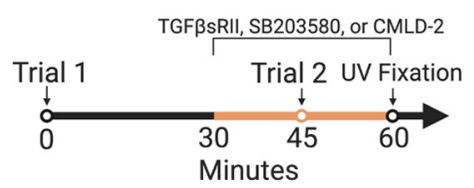

ELAV IP / IgG IP

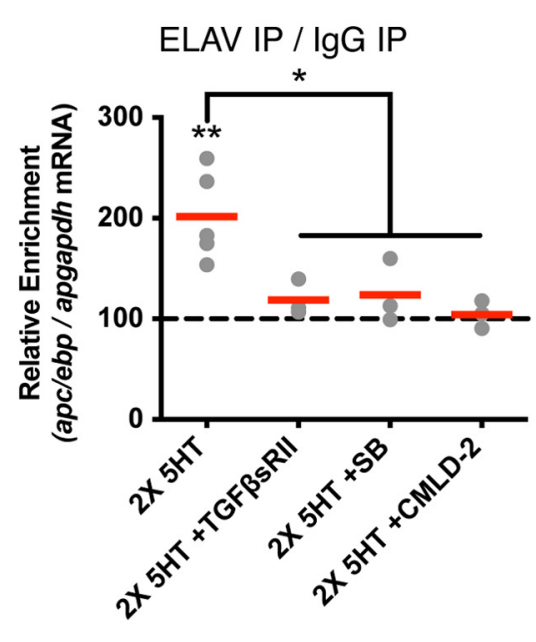

C
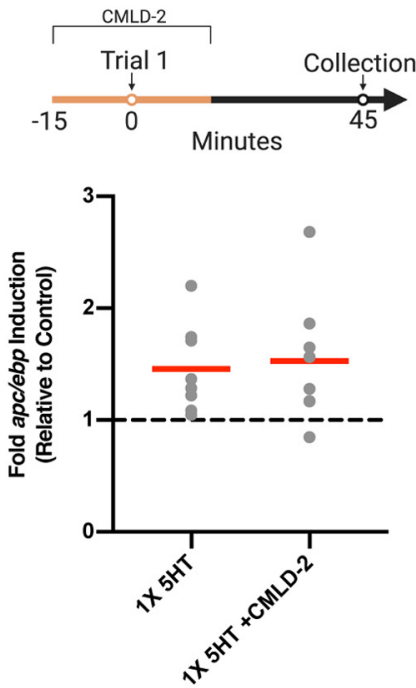

GFßsRII, SB203580, or CMLD-2

G

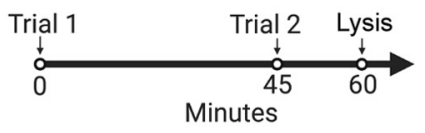

ApELAV Protein Levels

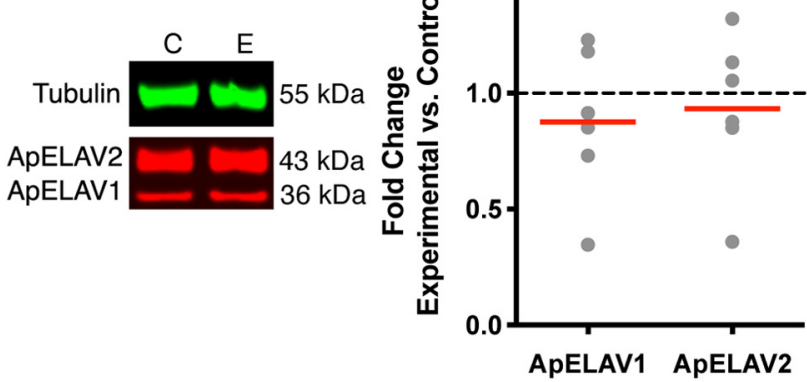

Figure 3. ApELAV proteins bind and stabilize apc/ebp mRNA downstream of p38 MAPK and TGF $\beta$ signaling. A, Following inhibition of basal transcription, apc/ebp mRNA is rapidly degraded in SN clusters, and this degradation is significantly accelerated by additional CMLD-2 treatment. $n=4-8 . * p<0.05$. $* * p<0.01$. $B$, Top, Experimental paradigm. SN clusters are collected at $1 \mathrm{~h}$ following the onset of Trial 1. Experimental ganglia receive two-trial training with CMLD-2 treatment (dark yellow line) from 30 min until collection at $1 \mathrm{~h}$. Bottom, Blocking the ApELAVmRNA interaction during Trial 2 blocks the increase in apclebp mRNA levels following two-trial training. $n=8$ or 9 . $* p<0.05$. C, Top, Experimental paradigm. SN clusters are collected at 
decrease in apclebp mRNA levels in experimental ganglia compared with contralateral within-animal control ganglia that received vehicle $\left(0.8 \%\right.$ acetonitrile and $\left.\mathrm{ddH}_{2} \mathrm{O}\right)$ (Fig. $3 \mathrm{~A}$; withingroup $t$ test: ActinoD: $0.6200 \pm 0.1081, n=4, p=0.0105$; ActinoD +CMLD-2: $0.3855 \pm 0.0460, n=8, p=0.0001$ ). A betweengroup comparison determined that addition of CMLD-2 accelerates apclebp mRNA degradation compared with ActinoD treatment alone (Fig. 3A; between-group unpaired $t$ test: ActinoD vs ActinoD + CMLD-2: $t=2.382, \mathrm{df}=10, p=0.0385)$.

In order to examine whether the ApELAV-apclebp mRNA interaction plays a critical role in increased $a p c / e b p$ mRNA levels during the two-trial training paradigm, ganglia received Trial 2 in the presence of CMLD-2. CMLD-2 treatment proceeded until $\mathrm{SN}$ cluster collection and lysis at $1 \mathrm{~h}$. Within-animal contralateral control ganglia were treated with vehicle and mock two-trial training. We found that $a p c / e b p$ mRNA levels in experimental ganglia were not significantly different from levels in within-animal contralateral control ganglia (Fig. 3B; within-group paired $t$ test: $2 \times 5$-HT +CMLD-2: $1.194 \pm 0.201, n=9, p=0.6195)$. Further, CMLD-2 significantly blocked the increase of Trial 2dependent apclebp mRNA levels compared with two-trial training with vehicle alone (Fig. $3 B$; within-group paired $t$ test: $2 \times$ 5-HT + Veh: $1.831 \pm 0.2892, n=8, p=0.0119$; between-group unpaired $t$ test: $2 \times 5$-HT + Veh vs $2 \times 5-\mathrm{HT}+\mathrm{CMLD}-2$ : $t=1.844, \mathrm{df}=15, p=0.0425$ ).

We have previously demonstrated that Trial 1 results in a transcription-dependent increase in $a p c / e b p$ mRNA levels at $45 \mathrm{~min}$ (Fig. 1A). In order to determine whether the effect of ApELAV-mediated stabilization of $a p c / e b p$ mRNA is specifically engaged by Trial 2 , we treated experimental ganglia with CMLD2 during Trial 1 and assayed apc/ebp mRNA levels at $45 \mathrm{~min}$. Within-animal contralateral control ganglia were treated with vehicle and mock Trial 1 . We found that CMLD-2 treatment did not block apc/ebp gene expression induced by Trial 1, demonstrating that ApELAV is specifically engaged by Trial 2 (Fig. 3C; within-group paired $t$ test: $1 \times 5$-HT + CMLD-2: $1.527 \pm 0.2002$,

\footnotetext{
$\leftarrow$

45 min following the onset of Trial 1. Experimental ganglia receive CMLD-2 treatment (dark yellow line) $15 \mathrm{~min}$ before Trial 1 and continues to $15 \mathrm{~min}$ after Trial 1. Bottom, Blocking the ApELAV-mRNA interaction during Trial 1 does not block the increase in apc/ebp mRNA levels at $45 \mathrm{~min}$. The $1 \times 5$-HT control data are from Figure $1 A . n=8$. D, Top, Experimental paradigm. SN clusters are collected at $1 \mathrm{~h}$ following the onset of Trial 1. Experimental ganglia receive Trial 1 and CMLD-2 treatment (dark and light yellow line) from 30 min until collection at $1 \mathrm{~h}$. TGF $\beta$ treatment (light yellow line) is from $45 \mathrm{~min}$ until collection at $1 \mathrm{~h}$. Bottom, Blocking the ApELAV-mRNA interaction blocks the within-group significant increase in apc/ ebp mRNA levels by TGF $\beta$ treatment. The $1 \times 5-\mathrm{HT}+\mathrm{TGF} \beta$ control group is from Figure 1C. $n=7$ or 8 . ${ }^{\#} p<0.2$. $* p<0.05$. $\boldsymbol{E}$, Top, Experimental paradigm. SN somata are UV-fixed and collected at $1 \mathrm{~h}$ following the onset of Trial 1 . Experimental ganglia receive two-trial training and are treated with TGF $\beta$ sRII, SB203580, or CMLD-2 (dark yellow line) from 15 min before Trial 2 until UV fixation at $1 \mathrm{~h}$. Bottom, Following two-trial training, there is a significant increase in ApELAV-apc/ebp mRNA interaction, which is blocked by treatment with TGF $\beta$ sRII, SB203580, or CMLD-2. Each data point represents the results of one experiment (SN clusters pooled from 8 animals). $* p<0.05$. $* * p<0.01 . n=3-5$. $\boldsymbol{F}$, Left, ApELAV1 and ApELAV2 are recognized by the mouse monoclonal anti-HuR (Santa Cruz Biotechnology) antibody at their respective predicted molecular weights. ApELAV1 is present in both gill and CNS. ApELAV2 demonstrates differential expression in gill and CNS. Tubulin is used as a loading control. Right, The antibody reacts strongly with recombinant ApELAV1GST (expression induced with IPTG). G, Top, Experimental paradigm. SN clusters are collected at $1 \mathrm{~h}$ following the onset of Trial 1. Experimental ganglia receive two-trial training and contralateral control ganglia receive mock two-trial training. Bottom, Left, Representative Western blot for ApELAV using tubulin as a loading control. Control (C) and experimental (E) indicate bands from a single SN cluster pair $(n=1)$. Right, There is no significant change in either ApELAV protein levels following two-trial training. $n=6$.
}

$n=8, p=0.0209$; between-group unpaired $t$ test: $1 \times 5$-HT vs $1 \times 5$ HT + CMLD-2: $t=0.2887, \mathrm{df}=14, p=0.7770$ ).

We next asked whether CMLD-2 could block the increase in $a p c / e b p$ mRNA levels resulting from treatment of ganglia, which had received Trial 1 and TGF $\beta 1$ treatment at $45 \mathrm{~min}$ (no Trial 2). When CMLD- 2 was administered with TGF $\beta 1$ treatment in lieu of Trial 2, no significant difference in $a p c / e b p$ levels between experimental $(1 \times 5-\mathrm{HT}+\mathrm{TGF} \beta+\mathrm{CMLD}-2)$ and within-animal control ganglia (mock Trial 1 and vehicle alone) was observed (Fig. $3 D$; within-group paired $t$ test: $1 \times 5$-HT + TGF $\beta$ +CMLD-2: $0.9825 \pm 0.1928, \quad n=7, \quad p=0.93,1$ outlier; see Materials and Methods). Although not significant, a betweengroup comparison revealed a trend toward blocking the increase in apclebp mRNA levels in the CMLD-2 treated versus TGF $\beta$ treatment alone groups (Fig. $3 D$; between-group unpaired $t$ test: $1 \times 5$-HT + TGF $\beta$ vs $1 \times 5$-HT + TGF $\beta+$ CMLD- $2: t=1.669$, $\mathrm{df}=13, p=0.1190)$.

\section{Blocking TGF $\beta$ signaling, p38 MAPK activation, and the ELAV-ARE interaction during Trial 2 eliminates the ApELAV-apc/ebp mRNA interaction}

Our hypothesis, that ApELAV is recruited by Trial 2 and binds to the apclebp transcript, predicts that the ApELAV-apc/ebp mRNA interaction should be increased at the $1 \mathrm{~h}$ time point following Trial 1 in ganglia, which receive two-trial training. To directly test this hypothesis, we performed a CLIP experiment followed by qPCR (CLIP-qPCR), to compare the physical interaction of apclebp mRNA with ApELAV between experimental (two-trial training) and within-animal control (mock two-trial training) groups. We used an antibody against $\mathrm{HuR}$ (see Materials and Methods; Fig. 3F), a mammalian member of the ELAV family, for immunoprecipitation of ApELAV-containing crosslinked ribonucleoprotein complexes. This antibody recognizes both Aplysia ELAV family members, ApELAV1 and ApELAV2 (Fig. 3F). Following two-trial training, we indeed found a significant increase in apc/ebp mRNA association with ApELAV in experimental ganglia compared with within-animal contralateral control ganglia (Fig. 3E; withingroup paired $t$ test: $2 \times 5$-HT: $201.6 \% \pm 19.89, n=5, p=$ 0.007), which strengthens the hypothesis that ELAV, by binding to apclebp transcript, promotes its stabilization at that time point.

If ApELAV is esponsible for stabilizing apc/ebp mRNA during Trial 2, thereby prolonging its expression to $1 \mathrm{~h}$ following Trial 1 , then blocking TGF $\beta$ signaling should block the ApELAV-apc/ebp mRNA interaction. We have previously shown that treatment with TGF $\beta$ sRII disrupted the increase in Trial 2-dependent apcl ebp mRNA level (Kopec et al., 2015). Treatment with TGF $\beta$ sRII resulted in the complete loss of the ApELAV-apclebp mRNA interaction at the same time point when assayed by CLIP-qPCR and compared with two-trial training alone (Fig. $3 E$; betweengroup unpaired $t$ test: $2 \times 5$-HT vs $2 \times 5$-HT + TGF $\beta$ sRII: $t=2.995, \mathrm{df}=6, p=0.0242$ ). No significant increase in ApELAV$a p c / e b p$ mRNA interaction was observed when experimental ganglia (which received two-trial training and TGF $\beta$ sRII) were compared with contralateral within-animal control ganglia, which received mock two-trial training and vehicle (0.1\% BSA in ASW) (Fig. 3E; within-group paired $t$ test: $2 \times 5$-HT + TGF $\beta$ sRII: $119.0 \% \pm 10.31, n=3, p=0.2067$ ), demonstrating that TGF $\beta$ signaling is required for the increase in ApELAV-apc/ebp mRNA interaction at that time point.

Activation of $\mathrm{p} 38 \mathrm{MAPK}$ is dependent on intact TGF $\beta$ signaling during Trial 2 (Fig. 2A), and SB203580 treatment during 
A
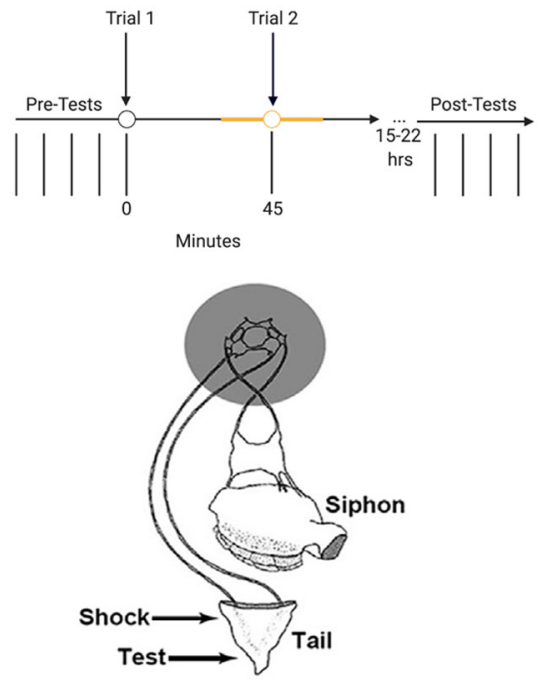

Figure 4. ApELAV-apc/ebp mRNA interaction is required for LTM formation. A, Top, Experimental paradigm. CMLD-2 treatment is indicated by yellow line. LTM is assessed by stimulating the test site before training, then $15-22 \mathrm{~h}$ after training and measuring the T-SWR. Bottom, Semi-intact preparation. Two-trial behavioral training is administered to the training site, and drug is applied to the isolated CNS chamber. B, Blocking the ApELAV-apc/ebp mRNA interaction during Trial 2 significantly disrupts LTM formation. $n=8 . * p<0.05$.

Trial 2 blocked the prolonged gene expression of apclebp (Fig. $2 B, C)$. Since $\mathrm{p} 38 \mathrm{MAPK}$ has previously been implicated in an intermediate role between TGF $\beta$ signaling and ELAV-mRNA binding (Bai et al., 2012), we predicted that blocking p38 MAPK should block the ability of ApELAV to interact with apclebp mRNA. We found that blocking p38 MAPK with SB203580 blocked the ApELAV-apc/ebp mRNA interaction compared with two-trial training alone (Fig. 3E; between-group unpaired $t$ test: $2 \times 5-\mathrm{HT}$ vs $2 \times 5-\mathrm{HT}+\mathrm{SB}: t=2.611, \mathrm{df}=6, p=0.0401)$. No significant increase in ApELAV-apc/ebp mRNA interaction was observed when two-trial trained ganglia treated with SB203580 were compared with contralateral within-animal control ganglia, which received mock two-trial training and vehicle $(0.1 \%$ DMSO) (Fig. 3E; within-group paired $t$ test: $2 \times 5-\mathrm{HT}+\mathrm{SB}$ : $124.0 \% \pm 18.35, n=3, p=0.3215)$. These results demonstrate that TGF $\beta$ signaling and $\mathrm{p} 38$ MAPK activation during Trial 2 are required for the interaction of ApELAV and $a p c / e b p$ mRNA.

To directly demonstrate whether CMLD-2 blocks the ApELAVapclebp mRNA interaction, we treated ganglia with CMLD-2 during Trial 2 and performed CLIP-qPCR. We found that treatment with CMLD-2 during Trial 2 significantly disrupted the ApELAV-apclebp mRNA interaction compared with two-trial training alone (Fig. $3 E$; between-group unpaired $t$ test: $2 \times 5$ HT vs $2 \times 5$-HT + CMLD-2: $t=3.579, \mathrm{df}=6, p=0.0117)$. No significant increase in ApELAV-apc/ebp mRNA interaction was observed when two-trial trained ganglia treated with CMLD-2 were compared with contralateral within-animal control ganglia, which had received mock two-trial training and vehicle (Fig. $3 E$; within-group paired $t$ test: $2 \times 5$-HT + CMLD-2: $104.4 \% \pm 7.91, n=3, p=0.6331)$. These results demonstrate the effectiveness of CMLD-2 as an inhibitor of the ApELAV-apc/ $e b p$ mRNA interaction in our two-trial paradigm.

Although we have demonstrated that Trial 2 results in an increase in ApELAV-apc/ebp binding, which is mediated by $\mathrm{p} 38$ MAPK, the possibility still remained that ApELAV could be exerting a stabilizing effect on apc/ebp through an increase in ApELAV protein levels. Thus, we assayed ApELAV protein levels in the pleural SNs following two-trial training. Our results revealed no difference in ApELAV protein levels between the experimental and within-animal contralateral control ganglia, which had received mock two-trial training (Fig. 3G; withingroup paired $t$ test: ApELAV1: $0.875 \pm$ $0.132, n=6, p=0.3875$; ApELAV2: $0.933 \pm$ $0.135, n=6, p=0.6382$ ).

\section{CMLD-2 disrupts the induction of behavioral LTM by Trial 2}

The molecular observations described thus far provide clear predictions for the role of $\operatorname{TGF} \beta$-mediated post-transcriptional regulation of apclebp mRNA by the RNAbinding protein ApELAV in the behavioral induction of LTM. We have previously shown that TGF $\beta$ signaling during Trial 2 is required for (1) the expression of $a p c /$ $e b p$ mRNA at the $1 \mathrm{~h}$ time point and (2) the induction of LTM for sensitization (Kopec et al., 2015). In the present paper, our data show that TGF $\beta$ signaling during Trial 2 provides stabilization of apc/ebp mRNA by means of increasing its association with ApELAV. Thus, collectively, our molecular data predict that the ApELAV-apc/ebp mRNA interaction during Trial 2 is required for the prolonged increase of $a p c /$ $e b p$ mRNA that is necessary for the induction of LTM. We directly tested this prediction in a final set of behavioral experiments examining LTM for sensitization of the tail-elicited siphon withdrawal reflex (T-SWR). We used the T-SWR semi-intact preparation (Sutton et al., 2001; Kopec et al., 2015) that permits the manipulation of the molecular environment of the CNS while directly assaying withdrawal responses (Fig. $4 A$; see Materials and Methods).

To test the hypothesis that the ApELAV-apc/ebp mRNA interaction is required during Trial 2 for LTM formation, we exposed the CNS to $100 \mu \mathrm{m}$ CMLD-2 or an equivalent volume of vehicle during Trial 2 (Fig. $4 A$ ). In the presence of vehicle, a within-group comparison revealed significant LTM for sensitization of the T-SWR (Fig. 4B; within-group paired $t$ test: Vehicle: $128.5 \% \pm 7.294, n=8, p=0.0127)$. In contrast, the induction of LTM was significantly disrupted when the ApELAV-apclebp mRNA interaction was blocked during Trial 2 (Fig. $4 B$; withingroup paired $t$ test: CMLD-2: $109.3 \% \pm 6.008, n=8, p=0.3268$ ). Moreover, a between-group comparison revealed a significant difference between vehicle and CMLD-2 groups (Fig. 4B; between-group unpaired $t$ test: Vehicle vs CMLD-2: $t=2.032$, $\mathrm{df}=14, p=0.0308$ ).

These behavioral data confirm the predictions derived from our molecular observations and support a general model in which TGF $\beta$ signaling in Trial 2 mediates RNA stabilization that is essential for LTM formation.

\section{Discussion}

Our results reveal a novel molecular mechanism underlying LTM formation: the stabilization of previously synthesized mRNA by a repeated training trial. Specifically, we show that apc/ebp mRNA is post-transcriptionally stabilized by the RNAbinding protein ELAV by a repeated training trial. This 


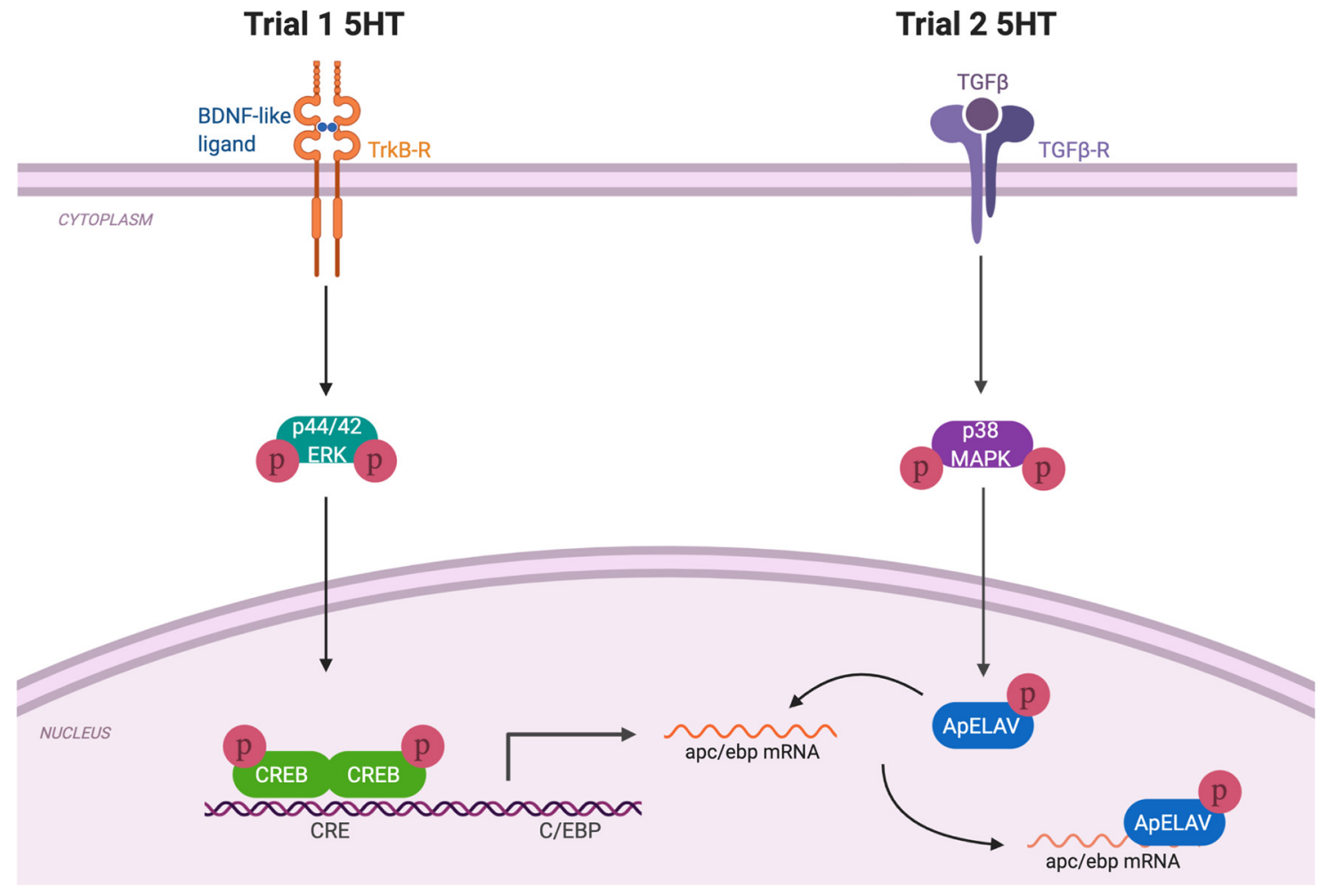

Figure 5. Working model of molecular mechanisms underlying apc/ebp transcript stabilization in two-trial LTM formation. Trial 15 -HT gives rise to an increase in CREB-mediated transcription and an increase in apc/ebp gene expression 45 min later through TrkB signaling and ERK activation (Kopec et al., 2015). When Trial 2 occurs at that time point (45 min), TGF $\beta$ signaling gives rise to an increase in p38 MAPK activation, resulting in an increase in ELAV-apc/ebp interaction. This interaction increases the stability of apc/ebp transcript and prolongs its expression to $1 \mathrm{~h}$, which is permissive for the induction of LTM.

stabilization is dependent on TGF $\beta$ signaling and p38 MAPK activity, which is required for the induction of LTM (Kopec et al., 2015). Our data support a model (Fig. 5) in which Trial 1 gives rise to TrkB signaling, resulting in an increase in CREBmediated transcription and an increase in apclebp gene expression 45 min later. During Trial 2, TGF $\beta$-like ligands act in SNs to activate ELAV through p38 MAPK causing an increase in its binding to apclebp mRNA, thereby stabilizing the transcript, resulting in a transcription-independent prolonged increase in $a p c / e b p$ mRNA level. Notably, our findings of apclebp mRNA stabilization following Trial 2 in cultured, isolated SNs (Figure $2 B$ ) point to an autocrine TGF $\beta$ signaling mechanism in SNs. These findings are consistent with ongoing work in our laboratory demonstrating that TGF $\beta$-specific intracellular signaling is engaged specifically following two-trial training in isolated SNs (Miranda et al., 2019). Finally, the ApELAV-mRNA interaction during Trial 2 is a prerequisite for LTM formation. These experiments provide novel evidence for a GF-mediated process in LTM formation, resulting from post-transcriptional regulation that modulates the stability of an immediate early gene transcript, which serves as a transcription factor required in LTM.

\section{C/EBP in LTM formation}

The C/EBP family of transcription factors (having 2 isoforms in Aplysia and 6 isoforms in mammals) are immediate early genes downstream of CREB (Alberini, 2009). C/EBPs, particularly the $\mathrm{C} / \mathrm{EBP} \beta$ and $\mathrm{C} / \mathrm{EBP} \delta$ isoforms, are regulated by learning-related stimuli across a wide range of species, as well as across diverse brain regions and learning tasks (Alberini et al., 1994; Alberini, 2009). Together with these studies, our findings indicate that $\mathrm{C} /$ EBP signaling is a significant molecular step mediating plasticity and memory formation. Interestingly, C/EBP contributes to the induction of GF ligands and receptors in (1) IGF-II in hippocampus (Chen et al., 2011), (2) VEGF-C and its receptor in lymphatic endothelial cells (Min et al., 2011), (3) TGF $\beta$ r-II in human embryonic stem cells (Takayama et al., 2014), and (4) NGF in cerebral cortex (McCauslin et al., 2006). This raises the intriguing possibility of a GF-mediated positive feedback loop during memory formation in which GF signaling upregulates C/EBP, which in turn increases GF ligand and/or receptor expression.

Here we have observed two phases of apc/ebp gene expression during LTM formation with two-trial training: (1) following Trial 1, a transcription-dependent increase in apc/ebp mRNA level; and (2) following Trial 2, a transcription-independent stabilization via the RNA-binding protein ApELAV, which prolongs the increase in $a p c / e b p$ mRNA level. This is a critical point of regulation since the presence of cis-acting regulatory elements on specific mRNAs, such as AREs, can modulate, or even counteract, the effect of increased transcription (Ross, 1995; Lee et al., 2015). The ARE RNA binding proteins ApAUF1 and ApELAV can bidirectionally regulate apc/ebp mRNA stability: ApAUF1 binding to the $3^{\prime} \mathrm{UTR}$ of $a p c / e b p$ induces the degradation of the transcript, and overexpression of ApAUF1 inhibits 5-HTinduced long-term facilitation in SN-MN coculture (Lee et al., 2012). Conversely, ApELAV binds to the same AU rich domain but stabilizes the transcript (Yim et al., 2006). Using the smallmolecule inhibitor CMLD-2 to block the ApELAV-apc/ebp mRNA interaction during the second trial of two-trial training, we demonstrated both the block of the increase in apclebp mRNA level and the disruption in the induction of LTM, underscoring the importance of this stabilizing mechanism for prolonging mRNA level and its critical role in LTM formation. Thus, the expression of ApAUF1 and ApELAV, or the ratio of these proteins, has the capacity to favor either the degradation or 
stabilization of $a p c / e b p$ mRNAs. Further, post-translational modification of these proteins, such as our demonstration of activation of ELAV by p38 MAPK (Fig. 3), could further influence the fate of the target mRNA.

In addition to apclebp, there are many other potential mRNAs that could be regulated by ApELAV. Indeed, it is predicted that $5 \%-8 \%$ of human mRNAs contain AREs that can be bound and influenced by RNA-binding proteins, including ELAV (Lee et al., 2015). In Aplysia, the immediate early gene and transcription factor ApEgr, which is rapidly and persistently regulated by LTM training (Cyriac et al., 2013; Herdegen et al., 2014), contains AREs within its 3'-UTR. Although it has not yet been determined, ApEgr is a likely target mRNA for ApELAV, especially considering our findings that ApELAV is activated following LTM training.

Prior studies have demonstrated a potential role for ELAV RNA-binding proteins in LTM formation. The present data significantly extend these initial studies in two ways: They demonstrate exactly when during LTM formation ELAV proteins are engaged, and they elucidate a mechanistic link between GF signaling, mRNA stabilization, and LTM formation. Specifically, in previous studies, the expression of the mammalian neuron-specific ELAV protein $\mathrm{HuC}$ has been shown to increase in mouse hippocampus following LTM training, and this increase was concomitant with an increase in its target mRNA GAP-43. Additionally, knockdown of $\mathrm{HuC}$ in mouse hippocampus resulted in impaired spatial learning (Quattrone et al., 2001). Other studies demonstrated that the expression of the mammalian neuron-specific ELAV protein $\mathrm{HuD}$ is increased following contextual fear conditioning in mice, and transgenic overexpression resulted in deficits in associative and spatial learning (Bolognani et al., 2004, 2007). Collectively, these results demonstrate an important role for ELAV proteins in LTM formation. However, they also pose potentially conflicting views of ELAV's actions, since both knocking out ELAV (Quattrone et al., 2001) and overexpression of ELAV (Bolognani et al., 2007) lead to memory deficits. The conflicting nature of these findings may be because of an experimental lack of temporal specificity. Using the two-trial paradigm in Aplysia, we are able to investigate mRNA regulation on the timescale of minutes. We find that ELAV target mRNA stabilization occurs without any appreciable change in ApELAV protein level, and the interaction between ApELAV and $a p c /$ $e b p$ mRNA is significantly increased following Trial 2. These findings allowed us to investigate the specific mechanistic link between a single, unique training stimulus (Trial 2), and mRNA stabilization, which we further demonstrate occurs through p38 MAPK activation downstream of TGF $\beta$ signaling.

Finally, we should emphasize that, in addition to transcript stabilization, other mechanisms of post-transcriptional regulation have previously been implicated in LTM formation in Aplysia (Rajasethupathy et al., 2009).

\section{TGF $\beta$ signaling and RNA-binding proteins}

Signaling through distinct GF families is specifically engaged, both spatially and temporally, during LTM formation (Kopec et al., 2015). In the first trial of a two-trial training paradigm, TrkB signaling at the $\mathrm{SN}$ synapse is required for apclebp gene expression $45 \mathrm{~min}$ following the onset of the trial, and TGF $\beta$ signaling is required at the $\mathrm{SN}$ soma during the second trial (at $45 \mathrm{~min}$ ) for prolonged increase in $a p c / e b p$ mRNA level. Here, we demonstrate that: (1) direct activation of TGF $\beta$ signaling (in the absence of 5 - HT at $45 \mathrm{~min}$ ) results in a transcription-independent increase in apc/ebp mRNA level, and (2) this effect is generated by recruiting ApELAV to bind and stabilize the apc/ebp transcript produced by TrkB signaling-dependent transcriptional mechanisms initiated by Trial 1 .

Interestingly, there is considerable evidence that TGF $\beta 1$ initiates stabilization of mRNAs via an RNA binding complex (Amara et al., 1995). In cardiac fibroblasts, TGF $\beta 1$ treatment induced HuR (a member of the mammalian ELAV family) translocation from the nucleus to the cytoplasm where it bound the ARE region of the $3^{\prime}$ UTR in TGF $\beta 1$ mRNA, thus stabilizing the mRNA and increasing protein level (Bai et al., 2012). These data suggest the intriguing possibility that, in addition to TGF $\beta$ RII signaling, initiating a cascade to prolong the expression of critical learning-related genes like $a p c / e b p$, other GF ligands could be induced and stabilized in the same way (including a TGF $\beta$ 1-like ligand itself). Indeed, GF ligands (Lim and Alkon, 2012) as well as their receptors (Balmer et al., 2001) can be regulated by ARERNA binding proteins.

The mammalian ELAV-like protein HuR is phosphorylated by PKC and p38 MAPK (Doller et al., 2007, 2008, 2011; Lafarga et al., 2009; Eberhardt et al., 2012; Mirisis and Carew, 2019). In our two-trial paradigm, we found that p38 MAPK activity was engaged through TGF $\beta$, and its activity was required both for the ApELAV-apc/ebp mRNA interaction and for the prolonged increase in apc/ebp mRNA. Indeed, phosphorylation of ELAV in many systems has been shown to (1) increase its binding affinity for AREs (Pascale et al., 2005; Doller et al., 2011; Eberhardt et al., 2012), (2) modulate the binding affinity of ELAV to specific types of AREs (Doller et al., 2010; Eberhardt et al., 2012), and (3) regulate its nucleocytoplasmic shuttling ability (Fan and Steitz, 1998; Wang et al., 2002; Doller et al., 2008, 2015; Bai et al., 2012). Interestingly, p38 MAPK activation has additionally been shown to inhibit the activity of destabilizing ARE-binding proteins, which would act to shift the balance toward mRNA stabilization (Briata et al., 2005).

In conclusion, the present results, taken with previous work, illustrate the importance of transcript regulation through GF signaling as a critical site of molecular interaction underlying LTM formation.

\section{References}

Alberini CM (2009) Transcription factors in long-term memory and synaptic plasticity. Physiol Rev 89:121-145.

Alberini CM, Ghirardi M, Metz R, Kandel ER (1994) C/EBP is an immediate-early gene required for the consolidation of long-term facilitation in Aplysia. Cell 76:1099-1114.

Amara FM, Chen FY, Wright JA (1995) Defining a novel cis element in the 3 '-untranslated region of mammalian ribonucleotide reductase component R2 mRNA: role in transforming growth factor-beta 1 induced mRNA stabilization. Nucleic Acids Res 23:1461-1467.

Bai D, Gao Q, Li C, Ge L, Gao Y, Wang H (2012) A conserved TGFbeta1/ HuR feedback circuit regulates the fibrogenic response in fibroblasts. Cell Signal 24:1426-1432.

Balmer LA, Beveridge DJ, Jazayeri JA, Thomson AM, Walker CE, Leedman PJ (2001) Identification of a novel AU-rich element in the $3^{\prime}$ untranslated region of epidermal growth factor receptor mRNA that is the target for regulated RNA-binding proteins. Mol Cell Biol 21:2070-2084.

Bolognani F, Merhege MA, Twiss J, Perrone-Bizzozero NI (2004) Dendritic localization of the RNA-binding protein $\mathrm{HuD}$ in hippocampal neurons: 
association with polysomes and upregulation during contextual learning. Neurosci Lett 371:152-157.

Bolognani F, Qiu S, Tanner DC, Paik J, Perrone-Bizzozero NI, Weeber EJ (2007) Associative and spatial learning and memory deficits in transgenic mice overexpressing the RNA-binding protein HuD. Neurobiol Learn Mem 87:635-643.

Brennan CM, Steitz JA (2001) HuR and mRNA stability. Cell Mol Life Sci 58:266-277.

Briata P, Forcales SV, Ponassi M, Corte G, Chen CY, Karin M, Puri PL, Gherzi R (2005) p38-dependent phosphorylation of the mRNA decaypromoting factor KSRP controls the stability of select myogenic transcripts. Mol Cell 20:891-903.

Brunelli M, Castellucci V, Kandel ER (1976) Synaptic facilitation and behavioral sensitization in Aplysia: possible role of serotonin and cyclic AMP. Science 194:1178-1181.

Chen DY, Stern SA, Garcia-Osta A, Saunier-Rebori B, Pollonini G, BambahMukku D, Blitzer RD, Alberini CM (2011) A critical role for IGF-II in memory consolidation and enhancement. Nature 469:491-497.

Cyriac A, Holmes G, Lass J, Belchenko D, Calin-Jageman RJ, CalinJageman IE (2013) An Aplysia Egr homolog is rapidly and persistently regulated by long-term sensitization training. Neurobiol Learn Mem 102:43-51.

Darnell R (2012) CLIP (cross-linking and immunoprecipitation) identification of RNAs bound by a specific protein. Cold Spring Harb Protoc 2012:1146-1160.

Dean JL, Sarsfield SJ, Tsounakou E, Saklatvala J (2003) p38 mitogen-activated protein kinase stabilizes mRNAs that contain cyclooxygenase- 2 and tumor necrosis factor AU-rich elements by inhibiting deadenylation. J Biol Chem 278:39470-39476.

Doller A, Huwiler A, Muller R, Radeke HH, Pfeilschifter J, Eberhardt W (2007) Protein kinase C alpha-dependent phosphorylation of the mRNAstabilizing factor HuR: implications for posttranscriptional regulation of cyclooxygenase-2. Mol Biol Cell 18:2137-2148.

Doller A, Pfeilschifter J, Eberhardt W (2008) Signalling pathways regulating nucleo-cytoplasmic shuttling of the mRNA-binding protein HuR. Cell Signal 20:2165-2173.

Doller A, Schlepckow K, Schwalbe H, Pfeilschifter J, Eberhardt W (2010) Tandem phosphorylation of serines 221 and 318 by protein kinase Cdelta coordinates mRNA binding and nucleocytoplasmic shuttling of HuR. Mol Cell Biol 30:1397-1410.

Doller A, Winkler C, Azrilian I, Schulz S, Hartmann S, Pfeilschifter J, Eberhardt W (2011) High-constitutive HuR phosphorylation at Ser 318 by $\mathrm{PKC} \delta$ propagates tumor relevant functions in colon carcinoma cells. Carcinogenesis 32:676-685.

Doller A, Badawi A, Schmid T, Brauss T, Pleli T, zu Heringdorf DM, Piiper A, Pfeilschifter J, Eberhardt W (2015) The cytoskeletal inhibitors latrunculin A and blebbistatin exert antitumorigenic properties in human hepatocellular carcinoma cells by interfering with intracellular HuR trafficking. Exp Cell Res 330:66-80.

Eberhardt W, Doller A, Pfeilschifter J (2012) Regulation of the mRNA-binding protein HuR by posttranslational modification: spotlight on phosphorylation. Curr Protein Pept Sci 13:380-390.

Eliscovich C, Shenoy SM, Singer RH (2017) Imaging mRNA and protein interactions within neurons. Proc Natl Acad Sci USA 114:E1875-E1884.

Fan XC, Steitz JA (1998) Overexpression of HuR, a nuclear-cytoplasmic shuttling protein, increases the in vivo stability of ARE-containing mRNAs. EMBO J 17:3448-3460.

Herdegen S, Holmes G, Cyriac A, Calin-Jageman IE, Calin-Jageman RJ (2014) Characterization of the rapid transcriptional response to longterm sensitization training in Aplysia californica. Neurobiol Learn Mem 116:27-35.

Kandel ER (2012) The molecular biology of memory: cAMP, PKA, CRE, CREB-1, CREB-2, and CPEB. Mol Brain 5:14

Kopec AM, Philips GT, Carew TJ (2015) Distinct growth factor families are recruited in unique spatiotemporal domains during long-term memory formation in Aplysia californica. Neuron 86:1228-1239.

Lafarga V, Cuadrado A, Lopez de Silanes I, Bengoechea R, FernandezCapetillo O, Nebreda AR (2009) p38 mitogen-activated protein kinaseand HuR-dependent stabilization of p21(Cip1) mRNA mediates the G (1)/S checkpoint. Mol Cell Biol 29:4341-4351.
Lee YS, Lee JA, Kaang BK (2015) Regulation of mRNA stability by AREbinding proteins in synaptic plasticity and memory. Neurobiol Learn Mem 124:28-33.

Lee YS, Choi SL, Jun H, Yim SJ, Lee JA, Kim HF, Lee SH, Shim J, Lee K, Jang DJ, Kaang BK (2012) AU-rich element-binding protein negatively regulates CCAAT enhancer-binding protein mRNA stability during longterm synaptic plasticity in Aplysia. Proc Natl Acad Sci USA 109:1552015525.

Lim CS, Alkon DL (2012) Protein kinase C stimulates HuD-mediated mRNA stability and protein expression of neurotrophic factors and enhances dendritic maturation of hippocampal neurons in culture. Hippocampus 22:2303-2319.

Marguerat S, Bähler J (2012) Coordinating genome expression with cell size. Trends Genet 28:560-565.

Marinesco S, Carew TJ (2002) Serotonin release evoked by tail nerve stimulation in the CNS of Aplysia: characterization and relationship to heterosynaptic plasticity. J Neurosci 22:2299-2312.

McCauslin CS, Heath V, Colangelo AM, Malik R, Lee S, Mallei A, Mocchetti I, Johnson PF (2006) CAAT/enhancer-binding protein delta and cAMPresponse element-binding protein mediate inducible expression of the nerve growth factor gene in the central nervous system. J Biol Chem 281:17681-17688.

Min Y, Ghose S, Boelte K, Li J, Yang L, Lin PC (2011) C/EBP-delta regulates VEGF-C autocrine signaling in lymphangiogenesis and metastasis of lung cancer through HIF-1alpha. Oncogene 30:49014909.

Miranda P, Kukushkin N, Mirisis AA, Schreibman M, Carew T (2019) Proteolytic processing of TGF $\beta$ provides a mechanism for precise temporal orchestration in long term memory formation. In: Society for Neuroscience Annual Conference. Chicago, IL: Society for Neuroscience.

Mirisis AA, Carew TJ (2019) The ELAV family of RNA-binding proteins in synaptic plasticity and long-term memory. Neurobiol Learn Mem 161:143-148.

Mirisis AA, Alexandrescu A, Carew TJ, Kopec AM (2016) The contribution of spatial and temporal molecular networks in the induction of long-term memory and its underlying synaptic plasticity. AIMS Neurosci 3:356384.

Mueller F, Senecal A, Tantale K, Marie-Nelly H, Ly N, Collin O, Basyuk E, Bertrand E, Darzacq X, Zimmer C (2013) FISH-quant: automatic counting of transcripts in 3D FISH images. Nat Methods 10:277278.

Muralidharan R, Mehta M, Ahmed R, Roy S, Xu L, Aube J, Chen A, Zhao YD, Herman T, Ramesh R, Munshi A (2017) HuR-targeted small molecule inhibitor exhibits cytotoxicity towards human lung cancer cells. Sci Rep 7:9694.

Pascale A, Amadio M, Scapagnini G, Lanni C, Racchi M, Provenzani A, Govoni S, Alkon DL, Quattrone A (2005) Neuronal ELAV proteins enhance mRNA stability by a PKCalpha-dependent pathway. Proc Natl Acad Sci USA 102:12065-12070.

Philips GT, Ye X, Kopec AM, Carew TJ (2013) MAPK establishes a molecular context that defines effective training patterns for long-term memory formation. J Neurosci 33:7565-7573.

Quattrone A, Pascale A, Nogues X, Zhao W, Gusev P, Pacini A, Alkon DL (2001) Posttranscriptional regulation of gene expression in learning by the neuronal ELAV-like mRNA-stabilizing proteins. Proc Natl Acad Sci USA 98:11668-11673.

Rajasethupathy P, Fiumara F, Sheridan R, Betel D, Puthanveettil SV, Russo JJ, Sander C, Tuschl T, Kandel E (2009) Characterization of small RNAs in Aplysia reveals a role for miR-124 in constraining synaptic plasticity through CREB. Neuron 63:803-817.

Ross J (1995) mRNA stability in mammalian cells. Microbiol Rev 59:423450.

Shobe J, Philips GT, Carew TJ (2016) Transforming growth factor beta recruits persistent MAPK signaling to regulate long-term memory consolidation in Aplysia californica. Learn Mem 23: $182-188$

Slone S, Anthony SR, Wu X, Benoit JB, Aube J, Xu L, Tranter M (2016) Activation of HuR downstream of p38 MAPK promotes cardiomyocyte hypertrophy. Cell Signal 28:1735-1741.

Soni S, Anand P, Padwad YS (2019) MAPKAPK2: the master regulator of RNA-binding proteins modulates transcript stability and tumor progression. J Exp Clin Cancer Res 38:121. 
Sutton MA, Masters SE, Bagnall MW, Carew TJ (2001) Molecular mechanisms underlying a unique intermediate phase of memory in Aplysia. Neuron 31:143-154.

Takayama K, Kawabata K, Nagamoto Y, Inamura M, Ohashi K, Okuno H, Yamaguchi T, Tashiro K, Sakurai F, Hayakawa T, Okano T, Furue MK, Mizuguchi H (2014) CCAAT/enhancer binding protein-mediated regulation of TGFbeta receptor 2 expression determines the hepatoblast fate decision. Development 141:91-100.

Varela-Rey M, Montiel-Duarte C, Osés-Prieto JA, López-Zabalza MJ, Jaffrèzou JP, Rojkind M, Iraburu MJ (2002) p38 MAPK mediates the regulation of alpha1(I) procollagen mRNA levels by TNF-alpha and TGF-beta in a cell line of rat hepatic stellate cells(1). FEBS Lett 528:133-138.

Wang W, Furneaux H, Cheng H, Caldwell MC, Hutter D, Liu Y, Holbrook $\mathrm{N}$, Gorospe M (2000) HuR regulates p21 mRNA stabilization by UV light. Mol Cell Biol 20:760-769.

Wang W, Fan J, Yang X, Furer-Galban S, Lopez de Silanes I, von Kobbe C, Guo J, Georas SN, Foufelle F, Hardie DG, Carling D, Gorospe M (2002) AMP-activated kinase regulates cytoplasmic HuR. Mol Cell Biol 22:3425-3436.

Wu X, Lan L, Wilson DM, Marquez RT, Tsao WC, Gao P, Roy A, Turner BA, McDonald P, Tunge JA, Rogers SA, Dixon DA, Aube J, Xu L (2015)
Identification and validation of novel small molecule disruptors of HuRmRNA interaction. ACS Chem Biol 10:1476-1484.

Yamashita M, Fatyol K, Jin C, Wang X, Liu Z, Zhang YE (2008) TRAF6 mediates Smad-independent activation of JNK and p38 by TGF-beta. Mol Cell 31:918-924.

Yim SJ, Lee YS, Lee JA, Chang DJ, Han JH, Kim H, Park H, Jun H, Kim VN, Kaang BK (2006) Regulation of ApC/EBP mRNA by the Aplysia AU-rich element-binding protein, ApELAV, and its effects on 5-hydroxytryptamine-induced long-term facilitation. J Neurochem 98:420-429.

Yoon JH, Gorospe M (2016) Cross-linking immunoprecipitation and qPCR (CLIP-qPCR) analysis to map interactions between long noncoding RNAs and RNA-binding proteins. Methods Mol Biol 1402:11-17.

Zhang F, Endo S, Cleary LJ, Eskin A, Byrne JH (1997) Role of transforming growth factor-beta in long-term synaptic facilitation in Aplysia. Science 275:1318-1320.

Zhang Y, Smolen P, Baxter DA, Byrne JH (2017) Biphasic regulation of p38 MAPK by serotonin contributes to the efficacy of stimulus protocols that induce long-term synaptic facilitation. eNeuro 4: ENEURO.0373-16.2017.

Zhao Y, Wang DO, Martin KC (2009) Preparation of Aplysia sensory-motor neuronal cell cultures. J Vis Exp 28:1355 